\title{
Experimental and analytical analyses of the cutting process in the deep hole drilling with BTA (Boring Trepanning Association) system
}

\author{
J. Thil ${ }^{1,2}$, B. HaddaG ${ }^{1}$, M. Nouari ${ }^{1, a}$, C. Barlier ${ }^{1,2}$ And L. Papillon ${ }^{3}$ \\ 1 Université de Lorraine, Laboratoire d'Energétique et de Mécanique Théorique et Appliquée, LEMTA CNRS-UMR 7563, \\ GIP-InSIC, 27 rue d'Hellieule, 88100 Saint-Dié-des-Vosges, France \\ 2 CIRTES, Centre Européen de Prototypage et Outillage Rapide, 29 bis rue d'Hellieule, 88100 Saint-Dié-des-Vosges, France \\ 3 AREVA NP, Usine de Chalon Saint-Marcel, 71380 Saint-Marcel, France
}

Received 17 June 2013, Accepted 22 December 2013

\begin{abstract}
This paper deals with analysis of the cutting process, on a macro and micro scale, in the deep hole drilling with BTA system. An experimental procedure is developed to highlight the impact of cutting speed and feed rate on the cutting process when machining the 18MND5 steel. Parameters based on dimensional characteristics of chips are introduced to quantify the morphology of chips generated by central, intermediate and external inserts of the complex BTA drilling tool. From observation of the chips morphology (flat, curved and spiral) and the measurement of the chips width, the provenance of each chip with respect to cutting inserts is identified. Then, the Chip Compression Ratio is evaluated for each cutting condition, indicating the amount of plastic strain in chips. Thanks to the introduction of a new parameter, denoted as Chip Fragmentation Ratio, it is found that the cutting speed has a little influence, compared to the feed rate, on the chips size. Based on this quantitative analysis, the optimal range of cutting conditions for the BTA deep hole drilling is discussed. It is mentioned that although increasing the feed rate promotes the chips fragmentation and increases the material removal rate (increasing productivity), an upper limit is to determine to prevent excessive flank wear. Also, the cutting speed should be limited to avoid excessive crater wear.
\end{abstract}

Key words: BTA deep drilling / cutting tests / chips characterisation / quantitative analysis / chip fragmentation / optimal cutting conditions

\section{Introduction}

Deep hole drilling is a particular case of drilling processes for machining holes with length-to-diameter ratio greater than five. Several technologies with main characteristics based on the surface roughness and straightness of the hole are available. Among them the BTA (Boring Trepanning Association) technology stands out as a technology which enables to perform deep holes, up to $1000 \mathrm{~mm}$ and more, with high productivity. Deep hole drilling with BTA system is used for machining holes where material removal rate is important. Adding to this the high exigency on the geometry of machined surfaces, especially concerning straightness of holes.

Application fields of this technology are numerous, such as aeronautics, naval, automotive and nuclear.

\footnotetext{
a Corresponding authors: badis .haddag@univ-lorraine.fr; mohammed.nouari@univ-lorraine.fr
}

In these contexts, requirements are severe and often machined components are very expensive. Despite the important issues related to the need of carrying out deep holes, the BTA deep hole drilling has not progressed technically as much as conventional drilling and has not attracted the same attention from the scientific community. The development of research on the deep hole drilling process could help to improve the reliability of cutting tools, to the physical understanding of the cutting process as well as to the selection of optimal cutting conditions. Since the origin of its development by Beisner during the 1940s [1], deep hole drilling, which is also with BTA system, has not followed the same technical evolutions and has not aroused the same scientific interests as other machining processes. The scientific production about BTA deep hole drilling remains relatively limited both in number and in diversity of authors and subjects (e.g. [1-30]). This can be explained in several ways and particularly by the exclusive industrial use of this type of technology 


\section{Nomenclature}

\begin{tabular}{|c|c|}
\hline \multicolumn{2}{|c|}{ Cutting parameters } \\
\hline$V_{\mathrm{c}}$ & Peripheral cutting speed $\left[\mathrm{m} . \mathrm{min}^{-1}\right]$ \\
\hline$f$ & Feed rate $\left[\right.$ mm.rev $\left.{ }^{-1}\right]$ \\
\hline \multicolumn{2}{|c|}{ Cutting tool parameters } \\
\hline$\varnothing$ & Tool diameter $[\mathrm{mm}]$ \\
\hline$\gamma$ & Tool-rake angle $\left[{ }^{\circ}\right]$ \\
\hline$\alpha$ & Clearance angles $\left[^{\circ}\right]$ \\
\hline$\alpha_{\mathrm{oc}}, \alpha_{\mathrm{oi}}, \alpha_{\mathrm{oe}}$ & Clearance angle of central, intermediate and external inserts, respectively $\left[^{\circ}\right]$ \\
\hline$\kappa_{\mathrm{rc}}, \kappa_{\mathrm{ri}}, \kappa_{\mathrm{re}}$ & Approach angle of central, intermediate and external inserts, respectively $\left[^{\circ}\right]$ \\
\hline \multicolumn{2}{|c|}{ Workmaterial parameters } \\
\hline$\rho$ & Workmaterial density $\left[\mathrm{g} \cdot \mathrm{cm}^{-3}\right]$ \\
\hline$R_{\mathrm{p} 0.2}$ & Tensile yield stress $[\mathrm{MPa}]$ \\
\hline$R_{\mathrm{m}}$ & Tensile strength $[\mathrm{MPa}]$ \\
\hline$H$ & Rockwell hardness [HRC] \\
\hline \multicolumn{2}{|c|}{ Chip morphology parameters } \\
\hline$w, \bar{w}$ & Chip width and average chip width, respectively $[\mathrm{mm}]$ \\
\hline$w_{\mathrm{c}}, w_{\mathrm{i}}, w_{\mathrm{e}}$ & Chip width of central, intermediate and external inserts, respectively $[\mathrm{mm}]$ \\
\hline$r_{\mathrm{c}}, r_{\mathrm{i}}, r_{\mathrm{e}}$ & Radial position of the cutting edge limit of central, intermediate and external inserts, respectively [mm] \\
\hline$t_{1}$ & Undeformed chip thickness $[\mathrm{mm}]$ \\
\hline$t_{2}, \bar{t}_{2}$ & Chip thickness and average chip thickness, respectively [mm] \\
\hline$l, \bar{l}$ & Chip length and average chip length, respectively $[\mathrm{mm}]$ \\
\hline$C C R$ & Chip Compression Ratio \\
\hline$C F R$ & Chip Fragmentation Ratio \\
\hline$m_{\mathrm{c}}, M_{\mathrm{c}}$ & Mass of one chip and $N_{c}$ chips, respectively [mg] \\
\hline & Average chip mass $[\mathrm{mg}]$ \\
\hline \multicolumn{2}{|l|}{ Subscripts } \\
\hline c, C.I. & Central Insert \\
\hline i, I.I. & Intermediate Insert \\
\hline e, E.I. & External Insert \\
\hline$N_{\mathrm{t}}$ & Number of measures of $t_{2}$ taken to calculate $\bar{t}_{2}$ \\
\hline$N_{\mathrm{c}}$ & Number of chips taken to calculate $\bar{m}_{\mathrm{c}}, \bar{l}$ and $C F R$ \\
\hline
\end{tabular}

that remains marginal compared to turning, milling and conventional drilling. Nevertheless, the emergence of new qualitative and quantitative constraints in several areas, including aerospace, automotive, wind energy and/or nuclear power arouse a renewed interest for the deep hole drilling by means of the BTA technology.

An important part of the basic concepts of conventional drilling applies to cases of deep hole drilling. Indeed, this is a machining in a confined environment. Nevertheless, the deep hole drilling with the BTA technique has its cutting specificities. The tool confinement in the workmaterial, associated with high length of the hole, generates in the tool head as well as in the workpiece extreme operating conditions (i.e. strong thermomechanical loading). In deep hole drilling the combination of chip removal, lubrication and localization of the thermomechanical loading in a confined cutting zone has a direct impact on the tool life and machining performances [2]. The main treated problems in scientific works concern the role of guide pads [1,3-13], the dynamic phenomena occurring during the machining [10-24] and the chip formation process [25,29].

The guide pads are one of technical specificities of the BTA deep hole drilling. They ensure good straightness of bores in view of the asymmetry of cutting forces, as stated in reference [3]. The asymmetry of cutting forces due to the guide pads position induces a burnishing of the hole surface [1]. It has been shown for the case of deep hole drilling that cumulative effects of cutting and polishing induce plastic deformation of the hole surface $[4,5]$. These are complex phenomena that affect both the hole surface roughness and cutting forces under action during machining [4-8]. As stated by Shaw and Oxford in reference [9], about $25 \%$ of the cutting power is consumed by the friction between guide pads and the hole surface. Richardson and Bhatti [1] have performed a complete investigation of the role of guide pads in the BTA deep hole drilling. They stated, for the considered BTA drilling tool, that about $63 \%$ of the cutting power is consumed by the chip removal, $24 \%$ is consumed by the burnishing effect and $13 \%$ is due to the friction.

The dynamic phenomena in deep hole drilling are also treated in several research works. The impact of coaxially between the BTA drilling tool and the machined hole on the cutting forces fluctuation has been treated in $[14,15]$. In $[13,16]$, the effect of the dynamic instability of the BTA drilling tool on the circularity of the hole has been studied. Two particular dynamic phenomena can be distinguished: chatter and spiral effects. The chatter effect is a frequent vibration phenomenon in deep hole drilling [17-22]. It corresponds to the auto-excitation vibrations in torsion motion, and conducts generally to tool wear acceleration as well as to a bad surface finish at the end of blind holes [23]. The spiral effect is another 
type of dynamic perturbations, described by many authors [19-22,24]. Two causes are identified as sources of dynamic perturbations, namely excessive wear of guide pads and dynamic instability of the boring bar (bending vibration) [19]. To prevent vibrations phenomena, studies based, among other, on statistical approaches are initiated $[10,20-22,24]$. The natural frequencies of the boring bar that composes the drilling system are calculated, which allow to characterize the stiffness of the system.

Post-analysis, i.e. after machining, of the BTA deep hole drilling process by examining the chips morphology, surface roughness, tool wear, hole straightness, etc., allows to understand the cutting process and therefore helps to choose optimal cutting conditions. For instance, analysis of the chips morphology in various machining processes has been conducted in several studies (e.g. [31-46]). Serrated, segmented or fragmented chips are suitable chips characteristics to reduce solicitation of the cutting tool and to facilitate the chips evacuation, particularly in drilling process where chips removal occurs in confined zone. In metal cutting, the chip morphology is an important indicator of the cutting process stability. Komanduri and Brown [31] classified chips into four types according to their morphology (wavy, discontinuous, segmented, and catastrophic shear chip). In drilling processes spiral or helical chips are often generated $[27,28]$, since the cutting speed varies along the radial direction of the cutting tool. Usually the chip morphology is quantified by the classical parameter, known as the chip compression ratio [46], which is an indicator of the amount of plastic strain in the chip. Other parameters are commonly used, such as chip segmentation frequency and chip segmentation length, in order to quantify the chip segmentation phenomenon (e.g. [41]). Recently, Atlati et al. [35] introduced a new parameter, called segmentation intensity ratio, based on the evolution of the plastic strain along the chip length, and Kouadri et al. [36] proposed other parameters based on dimension characteristics of the chip to quantify the chip segmentation phenomenon. Based on these parameters, they explained [35,36] the cutting force reduction as the cutting speed increase. Therefore, analysis of generated chips in the BTA deep hole drilling is an interesting way to characterise the cutting process after machining.

The objective of this paper is to characterise the BTA deep hole drilling process after cutting operation by qualitative and quantitative analyzes of the chips morphology on a macro and micro scale. Firstly, a description of the main deep hole drilling techniques is developed (Sect. 2). Secondly, parameters for the assessment of the chip morphology to be applied for the analysis of the chip formation process in the BTA deep hole drilling are described (Sect. 3). In Section 4, the experimental procedure is developed, describing the 18MND5 steel (AFNOR norm), equivalent to A533B steel (ASTM norm), as a workmaterial, the drilling machine, the BTA drilling tool and performed drilling tests. Finally, in Section 5, two analyses were performed, one is based on the macro and microscopic observations of chips generated by the central, intermediate and external inserts of the BTA drilling tool, and the other is based on the evaluation of defined parameters in Section 4, which are based on dimension characteristics of generated chips. Consequently, the impact of cutting conditions (cutting speed and feed rate) on the performance of the BTA deep hole drilling process when machining the 18MND5 steel has been highlighted. The Chip Fragmentation Ratio as a new parameter is introduced for this purpose. Using this parameter, as an indicator of the chips size, the risk of chips blockage in the boring bar channel has been discussed. Based on obtained results about the chips morphology and also on the risk of an excessive tool wear, a discussion has been reported in order to identify an optimal range of cutting conditions for the considered tool/workmaterial couple.

\section{Deep hole drilling techniques}

First of all, it is advisable to specify the process from technical point of view as well as associated technologies. As mentioned above, the BTA deep hole drilling can be considered as a particular case of drilling processes. To obtain deep holes with a certain quality, several parameters should be considered (adequate cutting speed and feed rate, guiding of the cutting tool in the hole, sufficient lubrication pressure, chip evacuation system...). The cutting operation can be performed with mono or multi-spindle to increase productivity. Generally, deep hole drilling tools are distinguished by their cutting fluid supply system as well as by their chips evacuation system [47]. As presented in Figure 1, three technologies are available for boring deep holes: Gundrill, BTA-DTS and BTA-STS. These technologies are compared in Table 1.

\subsection{Gundrill technique}

This technology concerns drilling in the mass (without initial hole) with a high hole surface quality (Ra between 0.1 and $3.2 \mu \mathrm{m}$, and a tolerance interval IT9). Gundrill tool, as shown in Figure 1a, is composed of one or several cutting edges, integrated fluid supply system as well as a straight flute along the drill axis whereby chips and cutting fluid are evacuated. The Gundrill technology enables machining holes with slightly better quality than the two following BTA deep hole drilling systems, but it offers less productivity (see Tab. 1).

\subsection{BTA-DTS technique}

This technique concerns drilling holes in the mass with high tool diameter and drilling length (see Fig. 1b). The bore is realized in a single operation with a tool composed of one or several cutting edges. The cutting fluid supply is carried out by the system of double-wall of the boring bar (see Fig. 1b). 
Table 1. Comparison of the main drilling technologies [47].

\begin{tabular}{cccccc}
\hline & $\begin{array}{c}\text { Drilling } \\
\text { diameter } \\
{[\mathrm{mm}]}\end{array}$ & $\begin{array}{c}\text { Ease of } \\
\text { implementation }\end{array}$ & Productivity & $\begin{array}{c}\text { Drilling } \\
\text { length/diameter } \\
\text { ratio }\end{array}$ & $\begin{array}{c}\text { Hole } \\
\text { Tolerance } \\
\text { roughness } \\
{[\mu \mathrm{m}]}\end{array}$ \\
\hline Gundrill & 0.9 to 41 & +++ & + & 100 & 0.1 to 3.2 \\
BTA- DTS & 18 to 185 & +++ & +++ & 100 & IT9 andIT10 \\
BTA- STS & 15 to 280 & ++ & +++ & 150 & to 3 \\
Legend: & + low & ++ medium & +++ high & & and IT10 3 \\
\hline
\end{tabular}

(a)

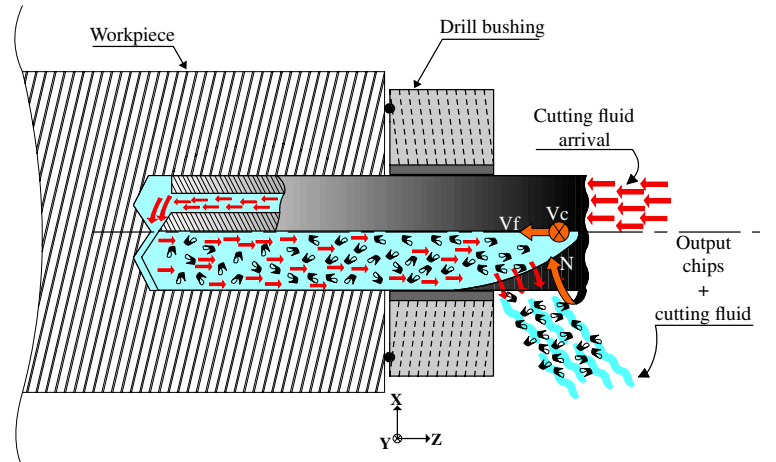

(b)

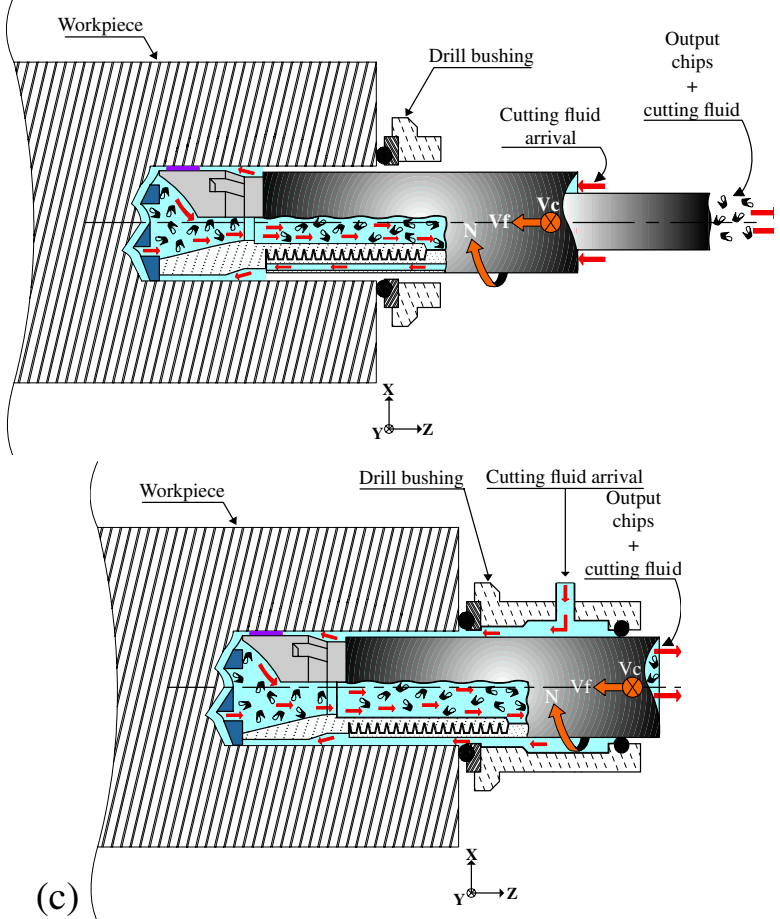

Fig. 1. Schematic representation of the deep hole drilling with (a) Gundrill system (3/4 drilling tool), (b) BTA-DTS or EJECTOR system and (c) BTA-STS system [47].

\subsection{BTA-STS technique}

The difference with the precedent system is in the principle of the cutting fluid supply. The STS system consists of a drill bush through which the cutting fluid enters and circulates up to the cutting zone on the periphery of the boring bar and the tool. Like the DTS system, the cutting fluid and chips are then evacuated from the inside of the tool head and the boring bar. This system is selected for very deep holes (see Fig. 1c). It allows reaching very high depths, up to $2000 \mathrm{~mm}$. The drilling tool is also composed of one or several cutting edges.

\section{Experimental work}

In order to analyse the cutting process in the BTA deep hole drilling, experimental tests have been performed. The workmaterial, the drilling tool, the drilling machine and performed drilling tests are described hereafter.

\subsection{Workmaterial}

The workmaterial is the Bainitic low alloy steel 18MND5, an iron-carbon based-steel, essentially used for the construction of reactors vessels of nuclear power plants. Several studies are conducted on similar steels in term of chemical composition, like 16MND5. Studies concerning the 16MND5 are mainly oriented to the integrity of reactors vessels and trait aspects of the materials tenacity [48-52]. According to Vereecke [51], originally the manganese composing the 18MND5 has been chosen to improve the hardenability and weldability of the steel, but also to trap sulphurs to form manganese sulphides, preferable to iron sulphides which have a negative effect on the mechanical resistance. For components with high thickness, nickel is added to the 18MND5 steel and carbon is reduced in order to improve its tenacity and weldability. The 18MND5 low alloy steel has good mechanical characteristics of tension and tenacity as indicated in Table 2 .

\subsection{BTA drilling tool}

The BTA deep hole drilling tool, designated as BTABTU14010-Ø19.30-P20-2D/63, used in experimental tests is illustrated in Figure 2. The tool has three cutting inserts and two guide pads. The inserts and pads, made of TiAlN coated carbide, are brazed to the tool body made of steel. The central insert, the first entering in contact with the workmaterial during cutting, is shifted radially 
Table 2. Mechanical characteristics of low alloy steel 18MND5.

\begin{tabular}{ccccc}
\hline$\rho$ & $H$ & $R_{p 0.2}$ & $R_{p 0.2}$ \\
{$\left[\mathrm{~g} \cdot \mathrm{cm}^{-3}\right]$} & {$[\mathrm{HRC}]$} & $\begin{array}{c}\left.T^{\circ}: \text { ambient }\right) \\
{[\mathrm{MPa}]}\end{array}$ & $\begin{array}{c}\left(T^{\circ}: 350{ }^{\circ} \mathrm{C}\right) \\
{[\mathrm{MPa}]}\end{array}$ & $\begin{array}{c}R_{m} \\
\left(T^{\circ}: \text { ambient }\right) \\
{[\mathrm{MPa}]}\end{array}$ \\
\hline 7.8 & $<20$ & 450 & 300 & 600 \\
\hline
\end{tabular}

(a)
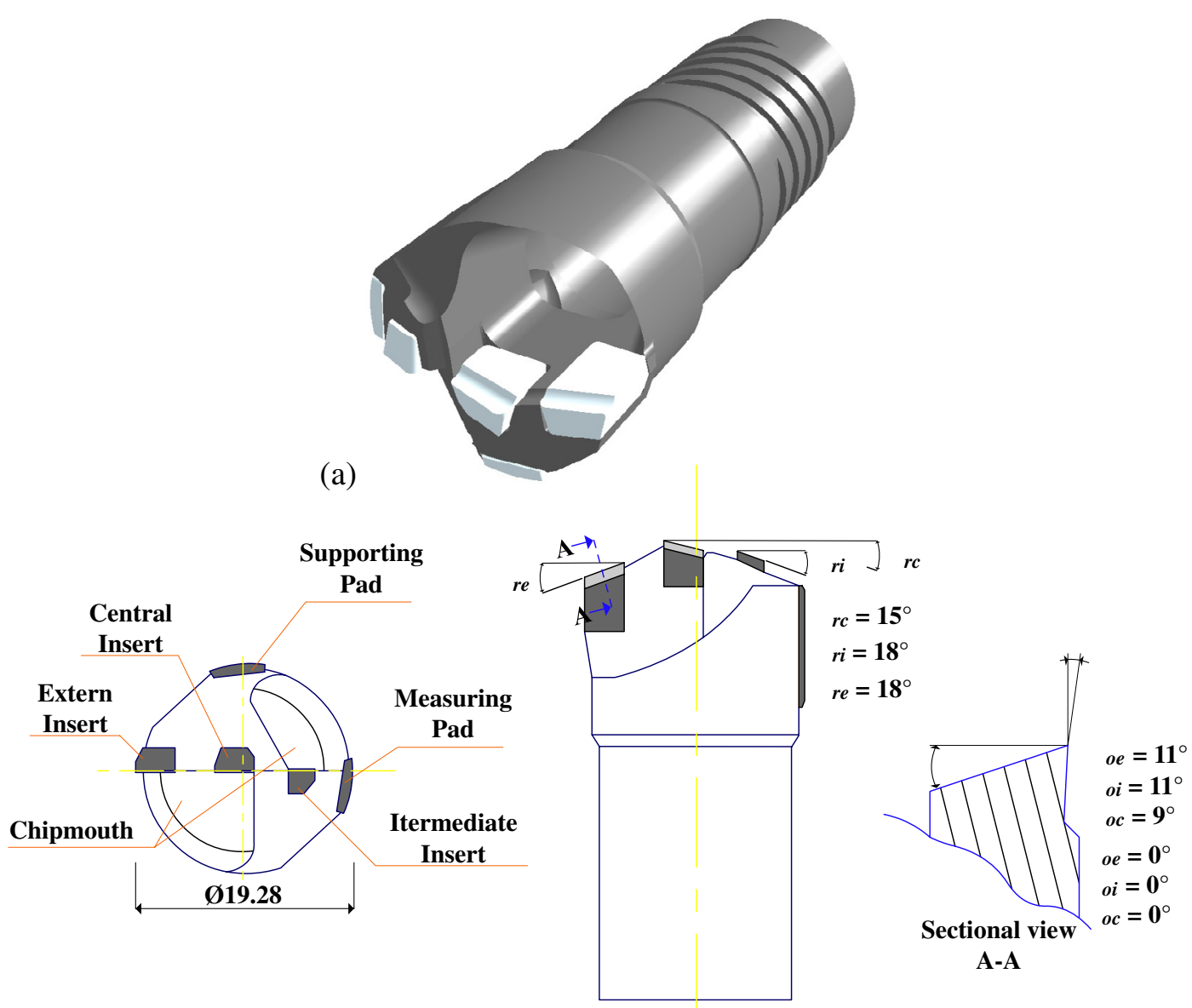

Sectional

(b)

Fig. 2. (a) BTA deep hole drilling tool (BTA-BTU14010-Ø19.30-P20-2D/63) and (b) its geometrical characteristics.

(radial offset equal $0.95 \mathrm{~mm}$ ) in order to minimize negative effects of the tangential cutting velocity close to zero in the vicinity of the tool axis. Richardson [1] indicates that the value of the radial offset of the central insert should be approximately $20 \%$ or 0.4 times the tool diameter. Gao [29] indicates that to enhance the tool tip with respect to strong mechanical stresses during machining, it is preferable that the value of the rake angle $(\gamma)$ is negative. However even a negative rake angle strength cutting inserts, this generates also a strong loading (axial force and torque) and the chip flow is not facilitated. In addition, the wear on the rake face could be more accentuated. The value of the approach angle $\left(\kappa_{\mathrm{r}}\right)$ varies between central, intermediate and external inserts, so that chips do not interfere with each other during the drilling process. Chip breakers are also suggested to facilitate chips fragmentation, and consequently to optimize their evacuation from the interior of the boring bar. Richardson [1] also suggests that the tools with diameter less than $9 \mathrm{~mm}$ can have a cutting zone composed of one part only, tools with diameter between 9 and $30 \mathrm{~mm}$ can have a cutting zone composed of two parts, and tools having a diameter greater than $30 \mathrm{~mm}$ can have a cutting zone composed of three parts. The recommendation of Richardson and Bhatti [1] takes into account the fact that it is more difficult to develop multi-inserts drilling tools having a small diameter.

\subsection{Drilling machine}

Drilling tests are performed on machining centre with horizontal multi-spindles $(\times 3)$. The machining centre is equipped with numeric command of type NUM 760 and 
Table 3. Experimental design.

\begin{tabular}{|c|c|c|c|c|c|c|}
\hline & $N^{\circ}$ test & $\begin{array}{c}\text { Cutting speed } \\
{\left[\mathrm{m} \cdot \mathrm{min}^{-1}\right]}\end{array}$ & $\begin{array}{l}\text { Feed rate } \\
{\left[\mathrm{mm} \cdot \mathrm{rev}^{-1}\right]}\end{array}$ & $\begin{array}{c}\text { Hole } \\
\text { length } \\
{[\mathrm{mm}]}\end{array}$ & $\begin{array}{c}\text { Lubrication } \\
\text { flow rate } \\
{\left[1 . \mathrm{min}^{-1}\right]}\end{array}$ & $\begin{array}{c}\text { Lubrication } \\
\text { pressure } \\
\text { [bar] }\end{array}$ \\
\hline \multirow{7}{*}{ 1st phase of tests } & 1 & 65 & \multirow{7}{*}{0.145} & \multirow{13}{*}{300} & \multirow{13}{*}{150} & \multirow{13}{*}{85} \\
\hline & 2 & 80 & & & & \\
\hline & 3 & 95 & & & & \\
\hline & 4 & 110 & & & & \\
\hline & 5 & 125 & & & & \\
\hline & 6 & 140 & & & & \\
\hline & 7 & 155 & & & & \\
\hline \multirow{6}{*}{ 2nd phase of tests } & 8 & & 0.1 & & & \\
\hline & 9 & \multirow{5}{*}{120} & 0.13 & & & \\
\hline & 10 & & 0.155 & & & \\
\hline & 11 & & 0.165 & & & \\
\hline & 12 & & 0.175 & & & \\
\hline & 13 & & 0.19 & & & \\
\hline
\end{tabular}

has a stroke of $1025 \mathrm{~mm}$ in the axial (feed) direction. The drilling machine is equipped with a monitoring system indicating, among other, the axial cutting force, i.e. in the feed direction. The cutting fluid supply is ensured by the BTA-STS technique (see Sect. 2).

\subsection{Experimental tests}

The methodology used for the experimental design, for the considered tool/workmaterial couple, consists in varying two cutting parameters: cutting speed and feed rate. For the considered cutting process, it aims to determine experimentally an optimal or stable range of cutting conditions for a given tool/workmaterial couple. Performed deep hole drilling tests are reported in Table 3 . The variation range of cutting parameters was chosen from recommended cutting conditions by the tool manufacturer [47]. For deep drilling 18MND5 steel, the recommended cutting speed is about $95 \mathrm{~m} \cdot \mathrm{min}^{-1}$ and the feed rate is about $0.145 \mathrm{~mm} \cdot \mathrm{rev}^{-1}$. During all drilling tests, no sign of accelerated or premature tool wear has been detected. Regular chips were obtained for each drilling test. The experimental setup can be thus qualified relatively stable and acceptable. From the technical point of view, tests were performed by series of four tests and with a new tool every time. Chips have been collected after each cutting test. BTA drilling tools have also been visually inspected after each test to ensure that no excessive tool wear occurred.

\section{Assessment of the chip morphology}

Analysis of the chips morphology enables to understand the cutting process, particularly in drilling processes. This gives indications about the stability of the cutting process. Indeed, for deep hole drilling processes this is more justified because the chip formation occurs in a confined environment where the cutting zone is not accessible to the observation by available experimental means. A significant number of research works (experimental and modelling) are dedicated to the analysis of the chip formation process in machining (e.g. [27-46,53]). Literature review reveals that very few research works have been dedicated to the analysis of the chip formation in deep hole drilling processes (e.g. [27-29]), particularly with the BTA system (e.g. [29]). Hereafter chips morphology parameters based on dimension characteristics of generated chips are introduced for this purpose.

\subsection{Engaged cutting edges width}

For the analysis of chips generated by cutting inserts of the BTA drilling tool, it is important to separate chips by their provenance, i.e. distinguish chips generated by each insert. One difference between chips is their width. Indeed, as shown in Figure 3, each cutting edge is engaged in the workmaterial with a certain width, calculated as follow:

$$
\begin{aligned}
w_{c} & =\frac{r_{c}}{\cos \left(\kappa_{\mathrm{rc}}\right)} \\
w_{i} & =\frac{r_{i}-r_{c}}{\cos \left(\kappa_{\mathrm{ri}}\right)} \\
w_{e} & =\frac{r_{e}-r_{i}}{\cos \left(\kappa_{\mathrm{re}}\right)}
\end{aligned}
$$

where $r_{c}, r_{i}, r_{e}$ and $\kappa_{\mathrm{r}}$ of each insert are geometric characteristics of the BTA drilling tool.

\subsection{Chip compression ratio}

Merchant [53] seems to be the first to propose parameters quantifying the chip morphology. He has proposed three parameters, namely chip length ratio, chip thickness ratio and chip width ratio. The Chip Compression Ratio $(C C R)$, as denoted by several authors (e.g. [46]), corresponds to the chip thickness ratio already proposed by Merchant [53]. Astakhov et al. (e.g. [46]) used extensively 


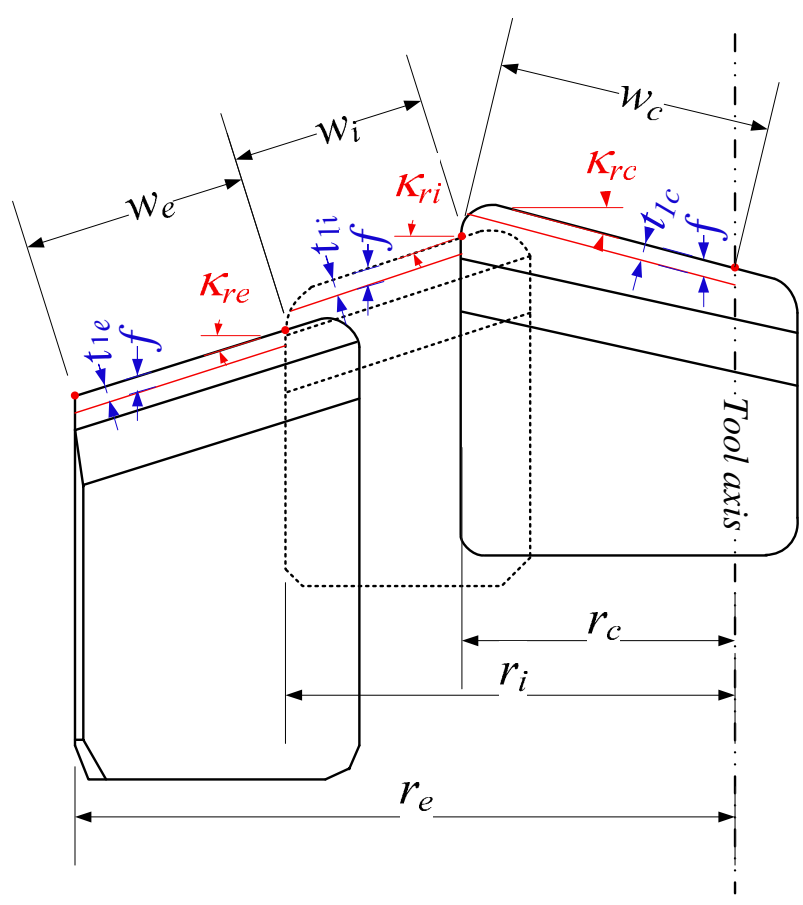

Fig. 3. Engaged cutting edge width $(w)$ and undeformed chip thickness $\left(t_{1}\right)$ of each insert of the BTA deep hole drilling tool.

this parameter for assessing the plastic strain occurring during chip formation. The $C C R$ parameter is expressed as follow:

$$
C C R=\frac{t_{2}}{t_{1}}
$$

In the frame of experimental analysis, the $C C R$ parameter can simply be evaluated by measuring the chip thickness $\left(t_{2}\right)$. For a continuous chip, the evaluation of the $C C R$ is clearly defined, since the chip thickness is constant along the chip. However, in the case of segmented or serrated chips an average value of the chip thickness should be defined $[35,36]$. As suggested by Astakhov and Shvets [46], the mean chip thickness can be assessed using the weight method to overcome this problem. Knowing the chip mass $\left(m_{c}\right)$, the chip length $(l)$, the chip width $(w)$ and the workmaterial density $(\rho), t_{2}$ is deduced from the relationship:

$$
t_{2}=\frac{m_{c}}{\rho w l}
$$

Since the chip length $(l)$ is also unknown and will be deduced (see the next section), in the present study, the $C C R$ parameter is assessed by defining an average value of the chip thickness $\left(\bar{t}_{2}\right)$. This is obtained by measuring the chip thickness from several points at the free surface of the chip. For $N_{t}$ measures $\left(t_{2}^{i}\right)$ of $t_{2}$, the $\bar{t}_{2}$ is calculated, and then the $C C R$ is deduced as follow:

$$
C C R=\frac{\bar{t}_{2}}{t_{1}}=\frac{\frac{1}{N_{t}} \sum_{i=1}^{i=N_{t}} t_{2}^{i}}{t_{1}}
$$

Note that, in practice six measures $\left(N_{t}=6\right.$, as shown farther in Fig. 9) are performed; three maximum peaks and three minimum peaks to determine an average value.

\subsection{Chip fragmentation ratio}

As mentioned in the last paragraph of the introduction, the chips size has an impact on the chips evacuation; smaller chips are easily evacuated by the cutting fluid using low lubrication pressure. Hence the quantification of the chips size, using adequate parameters, should help to choose optimal cutting conditions which improve the cutting performance (i.e. facility to evacuate chips). In metal machining the chip fragmentation depends highly on the amount of undeformed chip thickness $\left(t_{1}\right)$. A new parameter denoted Chip Fragmentation Ratio $(C F R)$ is then proposed in this study, which is defined as the ratio of chip length $(l)$ by undeformed chip thickness $\left(t_{1}\right)$ :

$$
C F R=\frac{l}{t_{1}}
$$

where the chip length $(l)$ is evaluated by the weight method as follow:

$$
l=\frac{m_{c}}{\rho w t_{2}}
$$

Hence the $C F R$ parameter is obtained for one chip as follow:

$$
C F R=\frac{l}{t_{1}}=\frac{m_{c}}{\rho w t_{1} t_{2}}
$$

Since there is a fluctuation on the chips length, to determine a representative value of the chips size, an average value of $l$ can be defined by taking a certain number of chips $\left(N_{c}\right)$ and by measuring their mass $\left(M_{c}\right)$. By determining an average value of the chip mass (i.e. $\bar{m}_{c}=\frac{1}{N_{c}} M_{c}$ ), the average chip length $(\bar{l})$ is deduced from relationship:

$$
\bar{l}=\frac{M_{c}}{N_{c} \rho w \bar{t}_{2}}=\frac{\bar{m}_{c}}{\rho w \bar{t}_{2}}
$$

Hence the $C F R$ parameter is assessed as follow:

$$
C F R=\frac{\bar{l}}{t_{1}}=\frac{\bar{m}_{c}}{\rho w t_{1} \bar{t}_{2}}
$$

In the case of BTA deep hole drilling, for each cutting condition chips are sorted by their origin (see chips generated by each insert of the BTA drilling tool in Sect. 5.1) and then for each set of chips the $C F R$ parameter is assessed. In practice, five chips generated by each insert are taken to assess the $C F R$, i.e. $N_{c}=5$.

\section{Results and discussion}

The BTA deep hole drilling tests are mainly analysed from the chips morphology characterisation. Macroscopic and microscopic observations of generated chips are performed. The influence of cutting conditions (cutting speed 
(a)
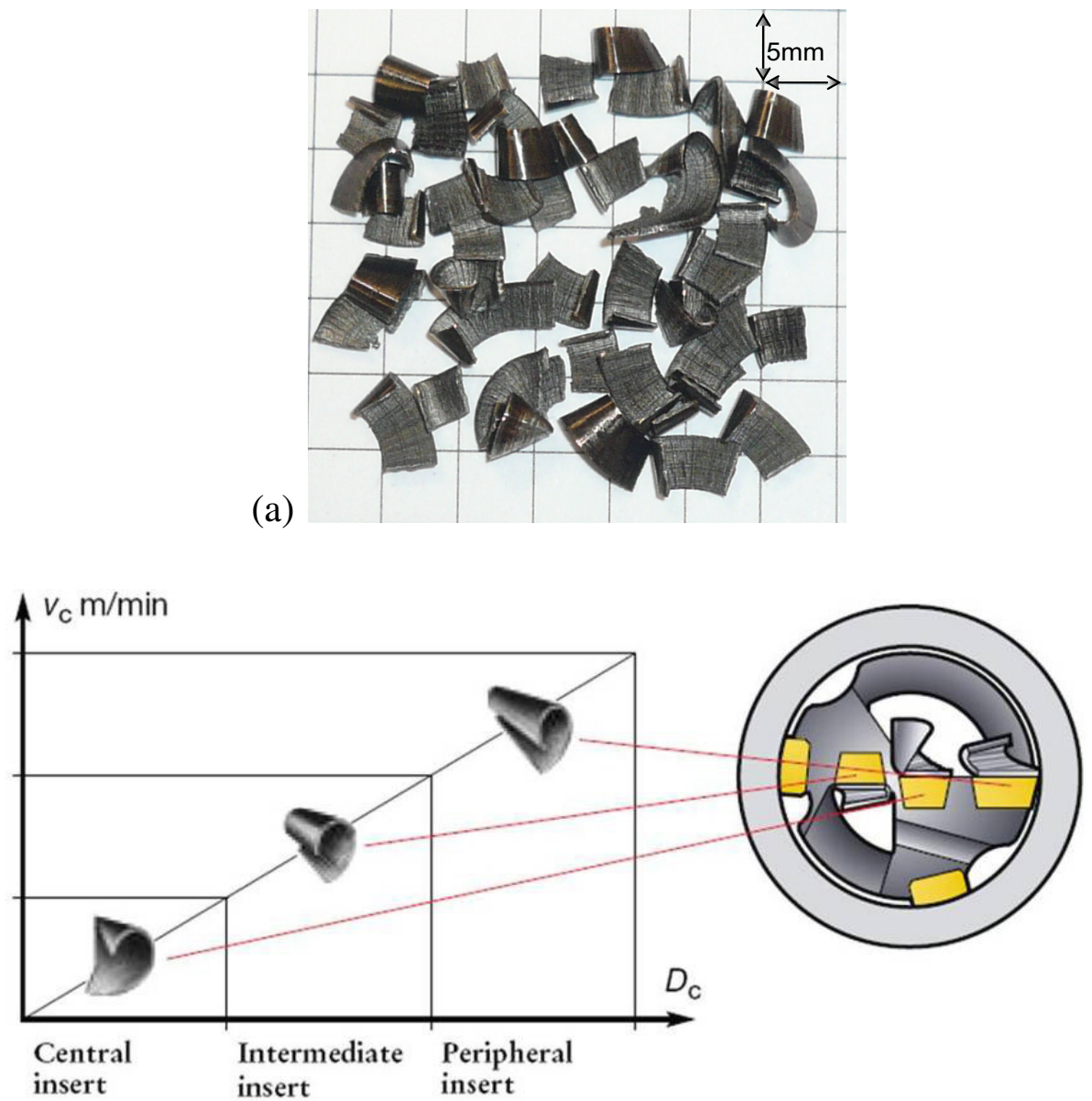

(b)

Fig. 4. (a) Generated chips for one cutting test and (b) identification of the chips morphology with respect to inserts of the BTA deep hole drilling tool (image (b) was taken from [47]).

and feed rate) on the cutting process is highlighted using the defined chip morphology parameters in Section 4. The analysis and interpretation of the obtained results should give some indications about optimal cutting conditions for the considered tool/workmaterial couple.

\subsection{Macroscopic characterisation of chips and their provenance}

For each drilling test, chips having different shapes are obtained, as shown in Figure $4 \mathrm{a}$. The first step of the analysis is to sort these chips from their origin, i.e. identify chips generated by each insert (central, intermediate and external inserts). Indeed, the particular geometric and kinematic configuration of the BTA deep hole drilling (position, inclination and tangential cutting velocity of inserts) has a direct effect on generated chips morphologies. As shown in Figure 4b, the central insert generates spiral chips which can be identified easily. This spiral shape is the consequence of abrupt change of the cutting speed along the engaged cutting edge of the central insert (tangential cutting velocity changes from zero to a certain value). While intermediate and external inserts generate more open chips which is more difficult to distinguish at first sight.

Since engaged cutting edges of inserts are different (each cutting edge is engaged in the workmaterial with a certain width), measured chips widths (see Figs. 5 and 6 ) compared to calculated ones by equation (1) are used to sort chips from their origin. In addition, chips width can be also found from the trace left by the chips flow on the rake face of each insert, as shown in Figure 7 . This completely validates the origin of each chip.

Tables 4 and 5 show a sorting of chips, in which it is possible to see a sample of five chips representative of chips generated by each insert for each test carried out. A first observation of chips at this macroscopic scale reveals a clear disparity in their morphology according to their origin (central, intermediate and external inserts). The geometry of active parts of inserts, cutting parameters and characteristics of the workmaterial are all factors which generate different chips in terms of shape, weight, size, etc. A second analysis of chips shows that the cutting speed (see Tab. 4) seems to have a limited influence on the morphology and fragmentation of chips. The cutting 

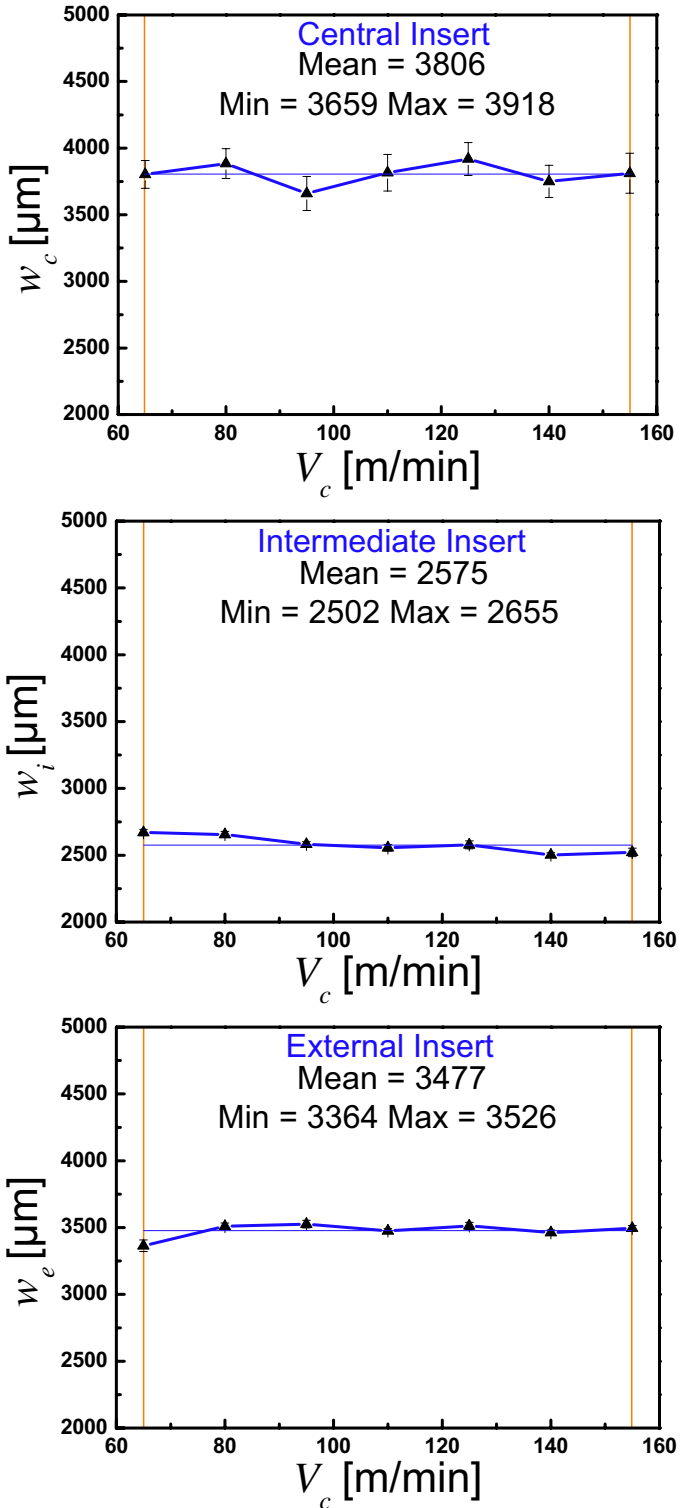

Fig. 5. Influence of the cutting speed on the chips width.

speed followed an evolution of approximately $140 \%$. The observation of chips reveals that they are of almost identical shape. On the contrary, the feed rate (see Tab. 5) seems to have a strong influence on the morphology and fragmentation of chips. The feed rate followed an evolution of approximately $90 \%$. It seems that the chip fragmentation is most effective for higher values of the feed rate. Section 5.3.3 discusses chips fragmentation in more detail, using the chip fragmentation parameter given by equation (9) (see Sect. 4.3).

Although this analysis, based on the observation of chips, is interesting, it is difficult to give precise conclusions about the impact of cutting speed and feed rate on the chip formation. Hence quantitative analysis seems to be necessary to highlight the impact of cutting conditions on the cutting process; this is performed in Section 5.3.
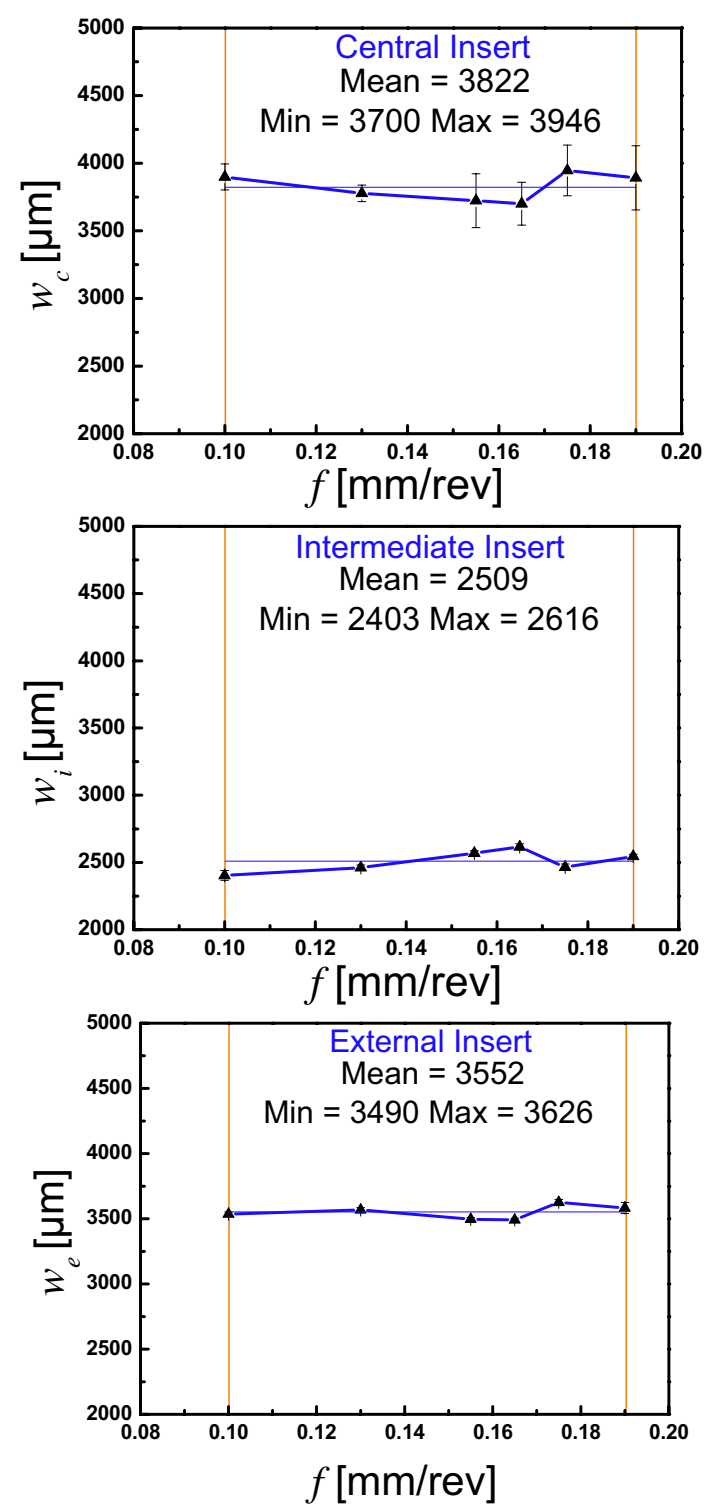

Fig. 6. Influence of the feed rate on the chips width.

\subsection{Microscopic characterisation of the chip morphology}

The spatial scale has an important role in the analysis of a machining process. Chips observations at the macroscopic scale, as shown in Tables 4 and 5, do not allow a detailed analysis of the chip formation by BTA deep hole drilling. Images at microscopic scale are then taken by means of a digital microscope KEYENCE ${ }^{\circledR}$ (see e.g. Figs. 8 and 9). Using distance measurements on micrographic images of chips, average chip width $(\bar{w})$ and average chip thickness $\left(\bar{t}_{2}\right)$ have been calculated for each chip type and each cutting condition (see Figs. 10 and 11). Note that, chip thickness measurements are taken in zones where the chip is less curved, for the facility of measurement.

The analysis of the chip morphology from images of Tables 6 and 7 reveals that it is not obvious to highlight 
(a)

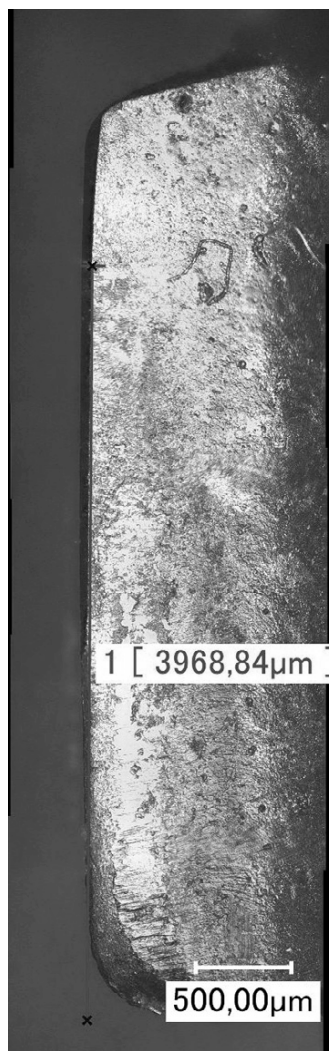

(b)

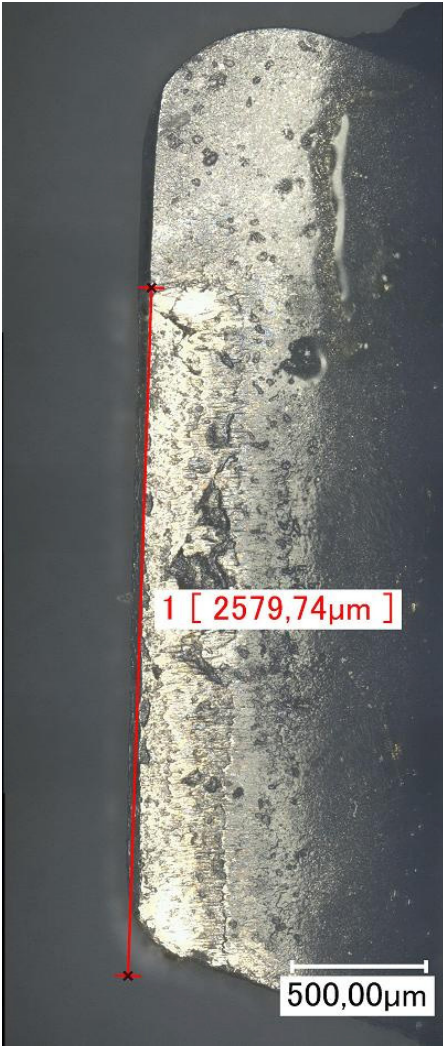

(c)

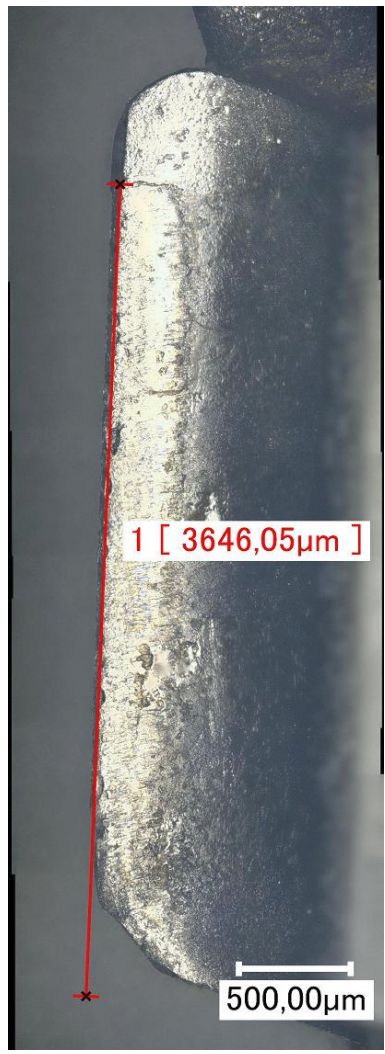

Fig. 7. Optical microscope observation of the trace left by chips flow on each rake face of the BTA drilling tool: (a) central, (b) intermediate and (c) external inserts. Estimation of the length of engaged cutting edges.

Table 4. Sort of generated chips with respect to inserts for different cutting speeds $\left(f=0.145 \mathrm{~mm}^{-\mathrm{rev}^{-1}}\right)$.

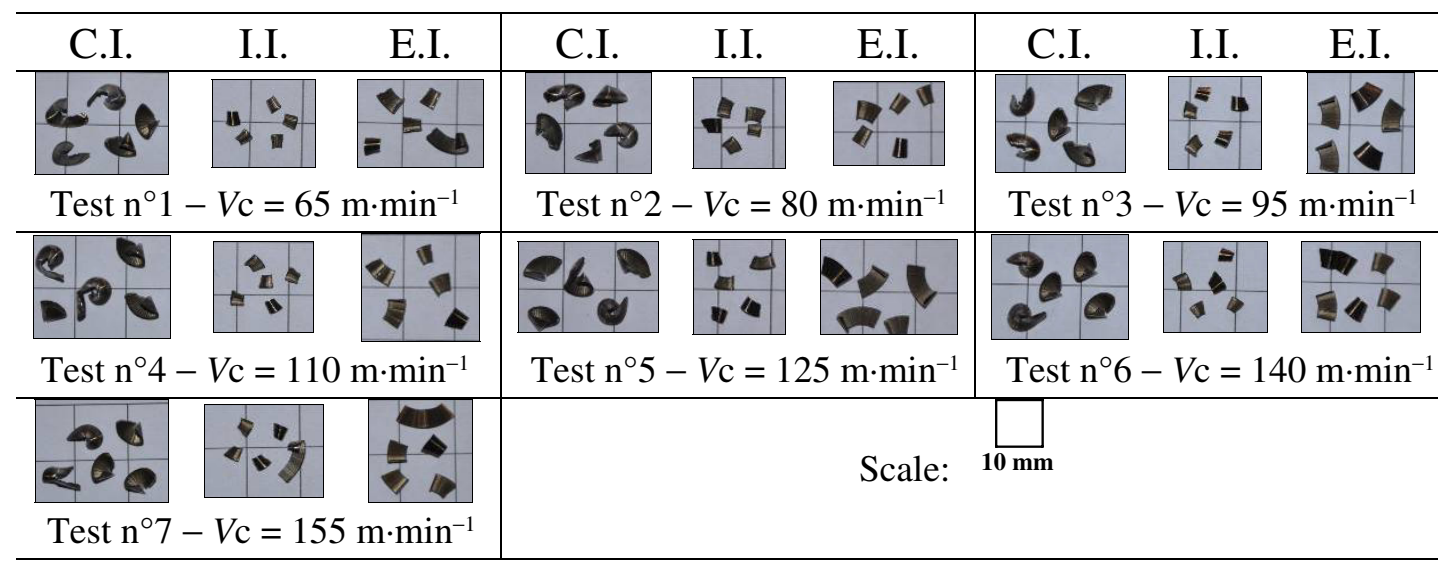

Table 5. Sort of generated chips with respect to inserts for different feed rates $\left(V_{\mathrm{c}}=120 \mathrm{~m} . \mathrm{min}^{-1}\right)$.

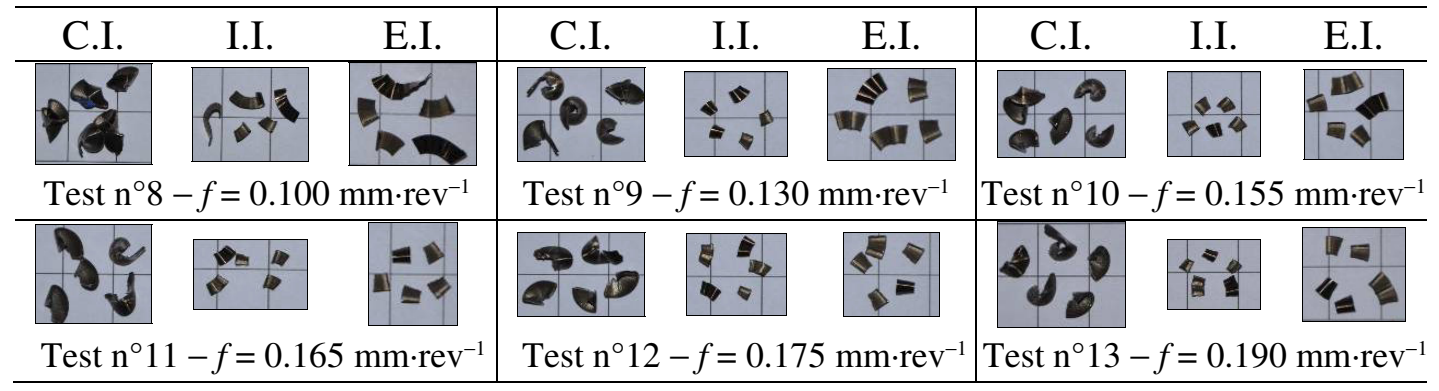


(a)

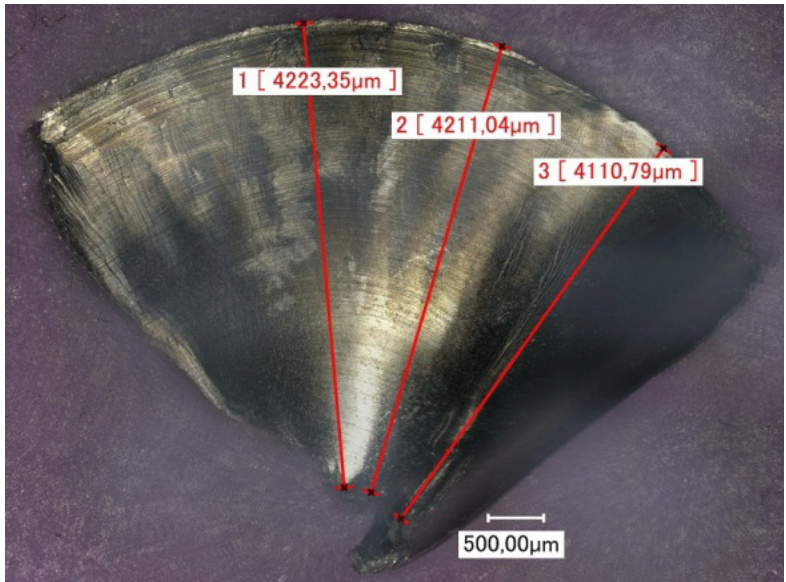

(b)

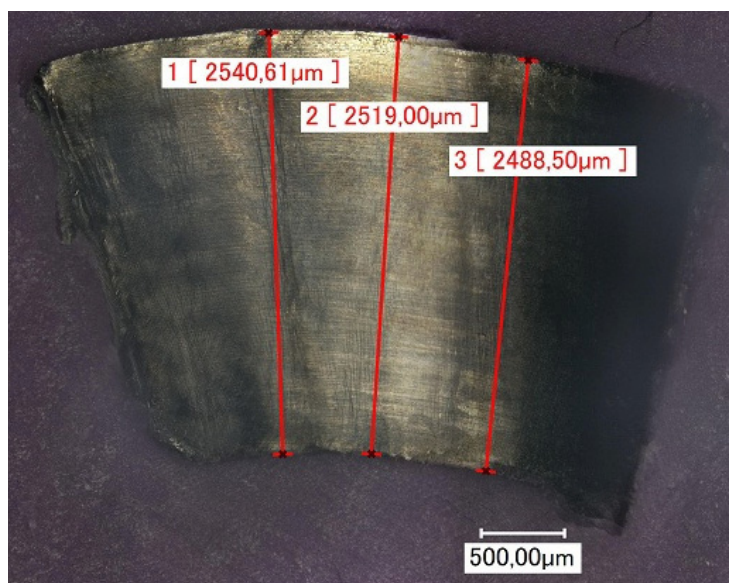

(c)

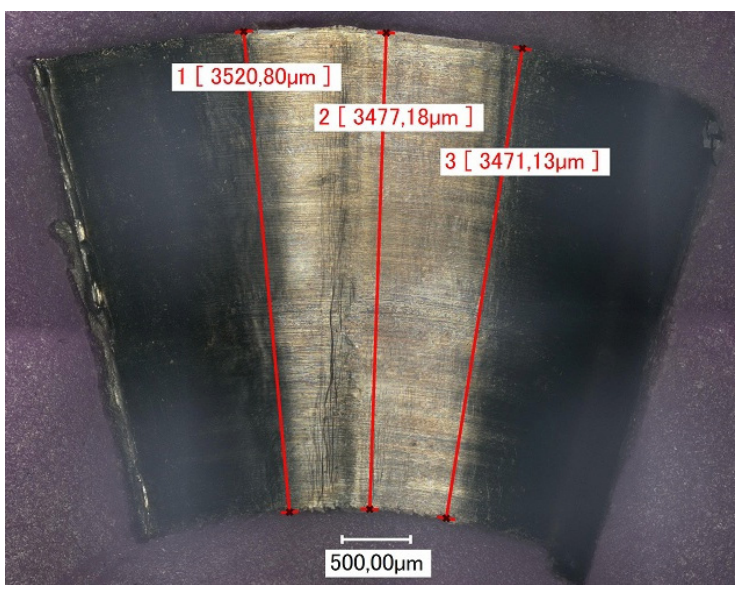

Fig. 8. Example of the width measurement on typical chips: Test $\mathrm{n}^{\circ} 5\left(V_{\mathrm{c}}=125 \mathrm{~m} \cdot \mathrm{min}^{-1}\right.$ and $\left.f=0.145 \mathrm{~mm} \cdot \mathrm{rev}^{-1}\right)$. (a) Central, (b) intermediate and (c) external inserts.

the impact of cutting conditions on each set of generated chips. Under any cutting condition, serrated or segmented chips are generated. In addition, the impact of cutting conditions on the intensity of chip segmentation is difficult to bring out. Hence, quantitative analysis of the chip morphology is necessary, as performed in the next section.

\subsection{Quantitative analysis of the chip morphology}

As shown in Tables 6 and 7, macroscopic and microscopic observations of generated chips have allowed a qualitative analysis of the cutting process. However it is not sufficient to highlight the impact of cutting conditions on the cutting process. A quantitative analysis is then necessary to give pertinent conclusions about the chip formation process in BTA deep hole drilling. The quantitative analysis is based on the assessment of different chip morphology parameters defined in Section 4. The variation of these parameters with respect to cutting conditions should bring out the impact of the later on the cutting process and thus allow refining the results discussion.

\subsubsection{Geometrical and measured chip width}

The influence of cutting speed on the measured chip width, as shown in Figure 10, does not indicate an upward or downward trend with respect to the variation of this cutting parameter. Widths of chips generated by all inserts are relatively constant. This indicates that plastic strain along the cutting edge in generated chips is very low, and that chips are formed under quasi plane strain condition (low lateral strain). This can be verified from Table 8, where the difference between the geometrical chip width and the measured one is less than $12 \%$ for all inserts. The same ascertainment about the impact of the feed rate on the chips width can be drawn.

\subsubsection{Chip thickness and chip compression ratio}

The evaluation of the chip thickness enables to estimate the amount of plastic strain in the chip, represented by the $C C R$ parameter. Figures $11 \mathrm{a}$ and $11 \mathrm{~b}$ show the variation of the average chip thickness $\left(\bar{t}_{2}\right)$ with cutting speed and feed rate, respectively. As shown in Figure 11a, $\bar{t}_{2}$ for central and intermediate inserts are quasi identical and tends to decrease at higher cutting speed, while $\bar{t}_{2}$ is quasi-independent of the cutting speed for the external insert. This suggests that beyond a certain level of cutting speed, the latter has a little influence on the chip thickness and therefore on the amount of plastic strain in generated chips. For this purpose, it is interest to verify if $\bar{t}_{2}$ of chips generated by central and intermediate inserts tends to $\bar{t}_{2}$ of chips generated by the external insert at high cutting speed. Additional tests are then necessary to be performed. In the present study, the cutting speed range is defined with respect to the capacity of the drilling machine (i.e. the maximum rotational speed of the spindle). Likewise, increasing the feed rate, as shown in Figure 11b, $\bar{t}_{2}$ increases quasi-linearly for each insert as expected, with more variation for central and intermediate inserts. For the external insert, $\bar{t}_{2}$ seems slightly more affected by the feed rate than by the cutting speed in the browsed range of cutting conditions. 
(a)

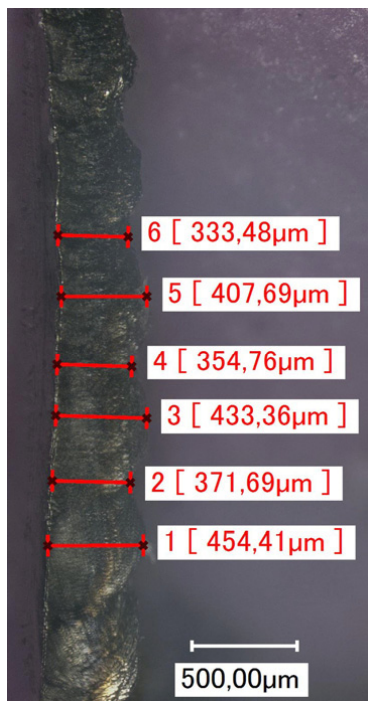

(b)

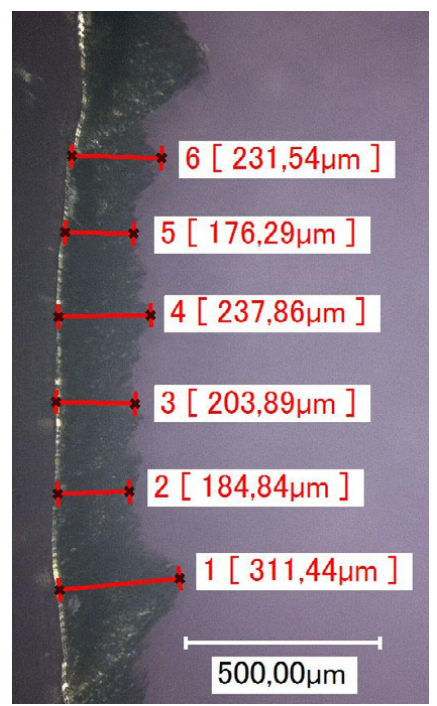

(c)

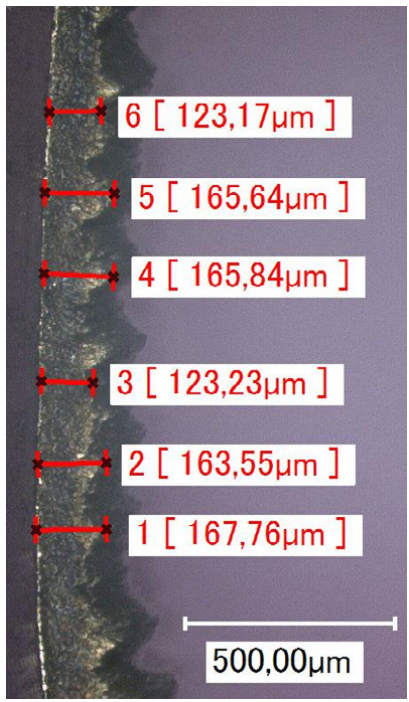

Fig. 9. Example of the measurement of thickness on typical chips: Test $\mathrm{n}^{\circ} 5\left(V_{\mathrm{c}}=125 \mathrm{~m} \cdot \mathrm{min}^{-1}\right.$ and $\left.f=0.145 \mathrm{~mm} \cdot \mathrm{rev}^{-1}\right)$. (a) Central, (b) intermediate and (c) external inserts.

Table 6. Observed chips morphology for different cutting speeds $\left(f=0.145 \mathrm{~mm} \cdot \mathrm{rev}^{-1}\right)$, depending on their origin.

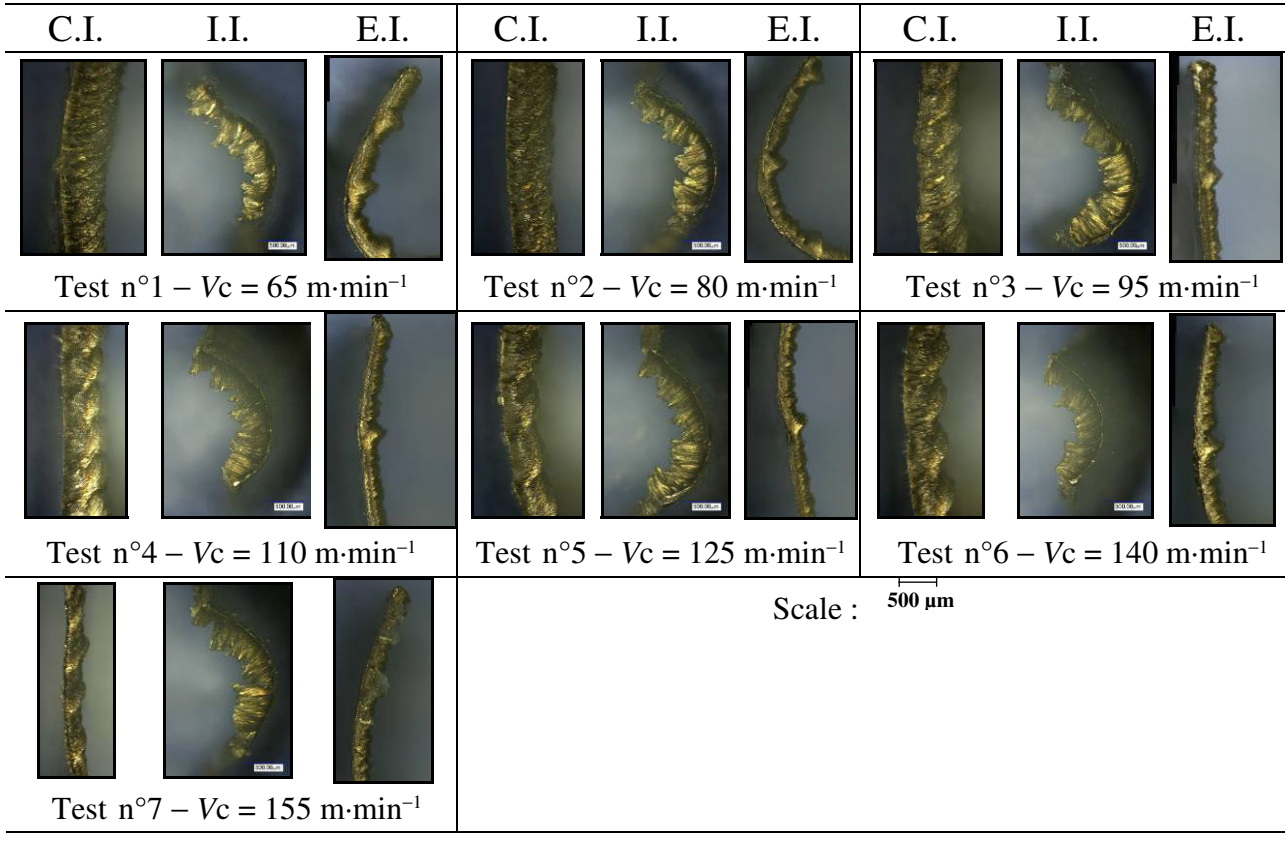

The $C C R$ parameter allows quantifying the average plastic strain occurring in the removed layer of the workmaterial, and therefore gives an insight about the consumed cutting energy per insert. In order to estimate the amount of plastic strain in generated chips by each insert of the BTA drilling tool as function of cutting conditions, the $C C R$ parameter is assessed using the measured chip thickness (see Fig. 11) and the undeformed chip thickness, as shown in Figure 12. From Figure 12a, $C C R$ as function of the cutting speed is higher for central and intermediate inserts. This is due to the fact that for specified rotation speed of the BTA drilling tool, the average tangential cutting speed is different between inserts (inserts penetrate in the workmaterial with different cutting velocities). As stated by Astakhov and Shvets [46] and Kouadri et al. [36], $C C R$ generally decreases with the increase of cutting speed. This corroborates results shown in Figure 12a. Noting that for the external insert $C C R$ seems quasi-independent of the cutting speed. This suggests that there is a certain amount of cutting speed beyond which it has little influence on the chip thickness. With the variation of the feed rate, as shown in Figure $12 \mathrm{~b}$, the external insert penetrates in the workmaterial always with higher cutting speed than intermediate 
Table 7. Observed chips morphology for different feed rates $\left(V_{c}=120 \mathrm{~m} / \mathrm{min}\right)$, depending on their origin.

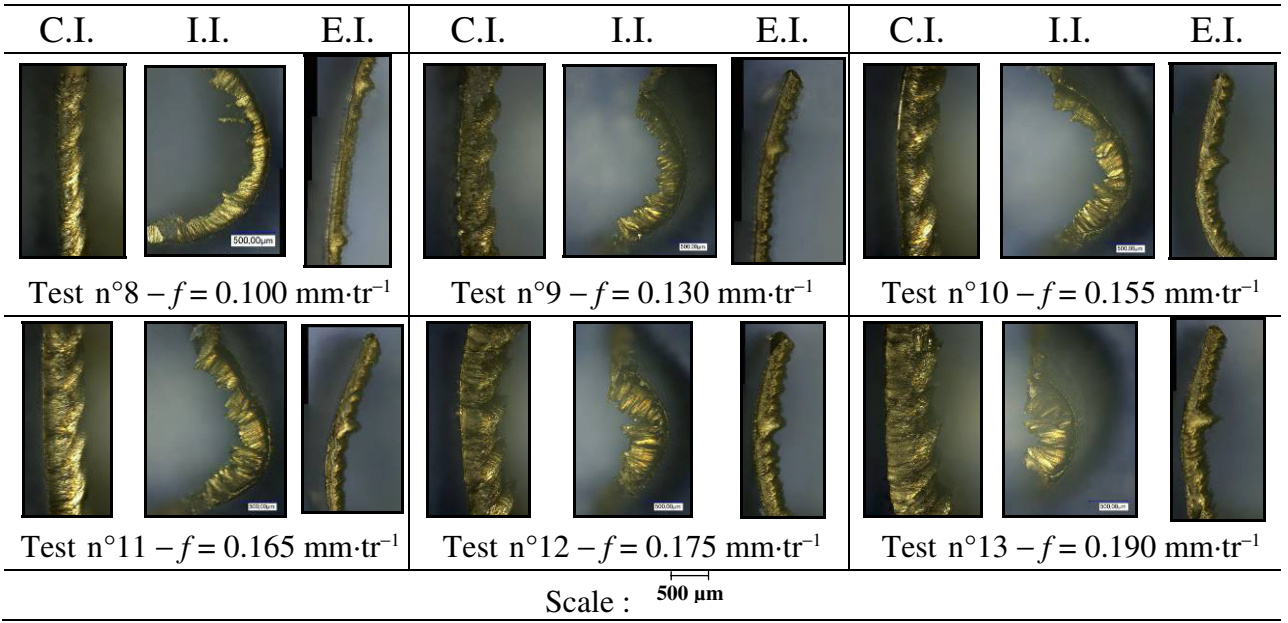
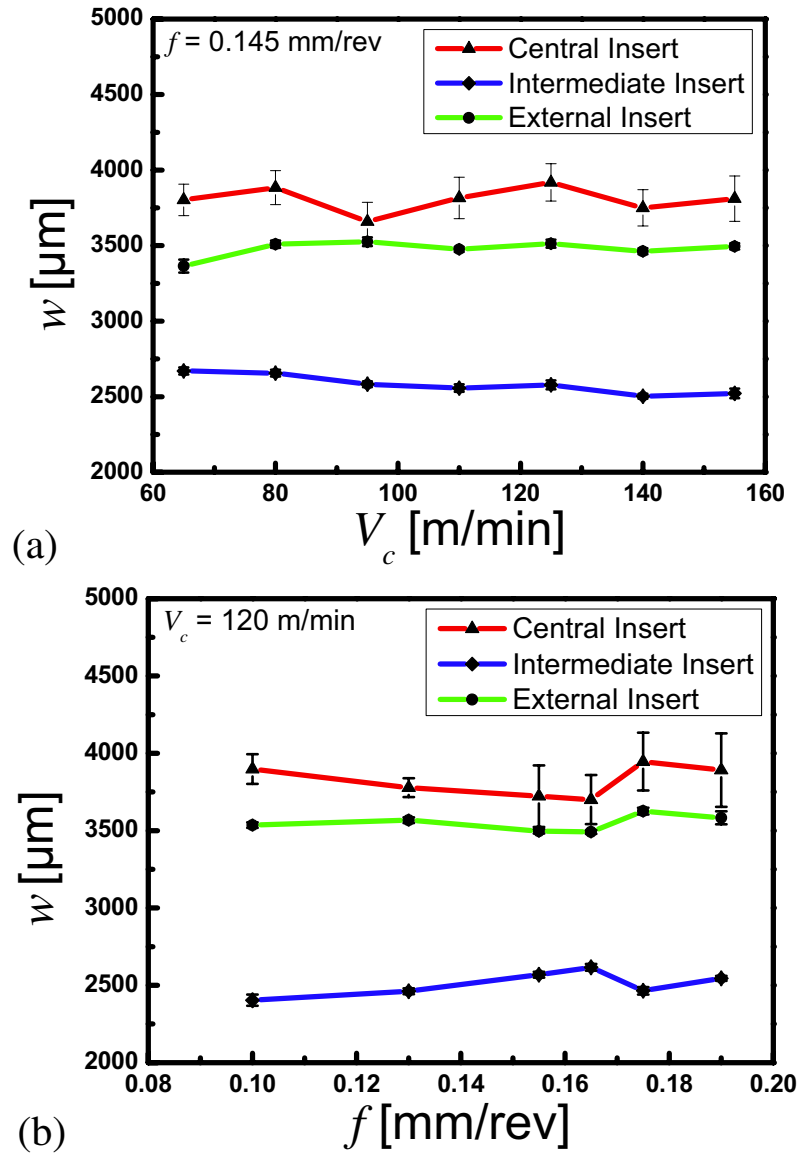

Fig. 10. Chips width as function of (a) cutting speed and (b) feed rate.

and central inserts. This result is also coherent with the work of Kouadri et al. [36]. In a nutshell, for a given cutting conditions (rotation cutting speed and feed rate), the amount of plastic strain in chips generated by the external insert is the lower since the cutting speed is higher.
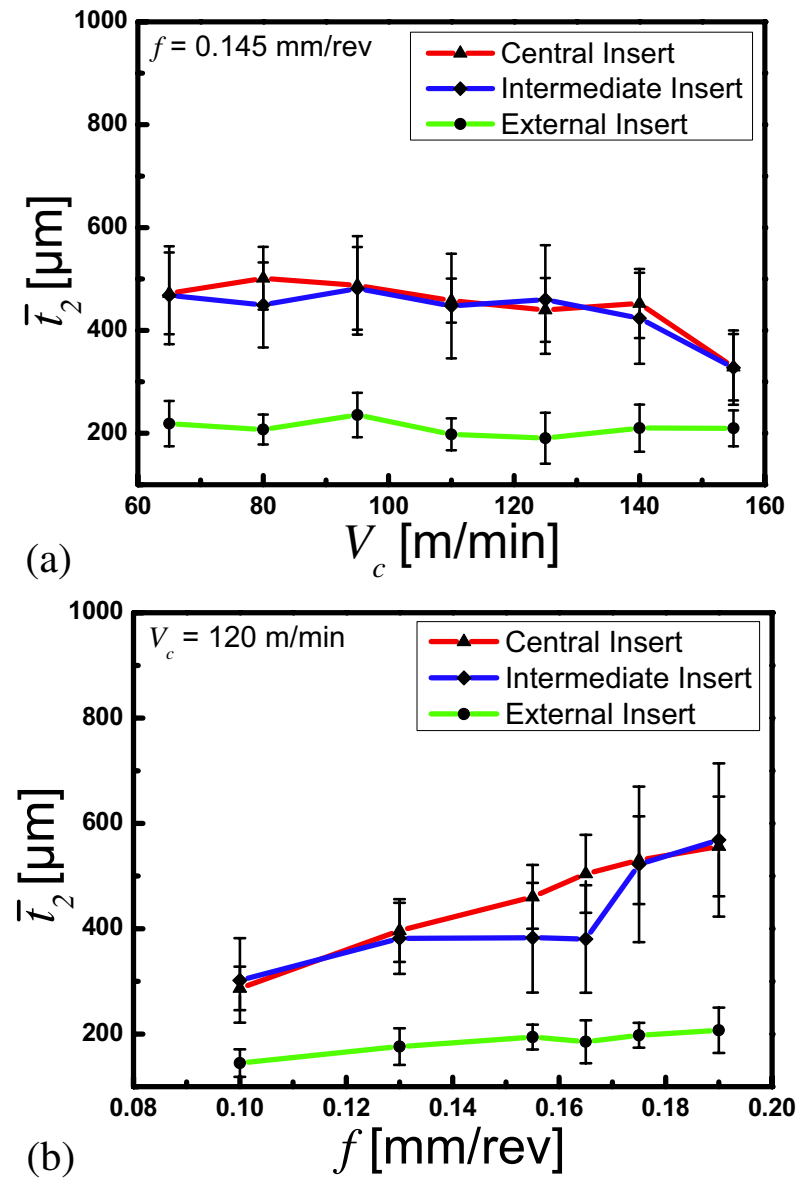

Fig. 11. Chip thickness as function of (a) cutting speed and (b) feed rate.

\subsubsection{Chip length and chip fragmentation ratio}

The chips evacuation depends highly on the chips size. Indeed, small size chips will be easily evacuated from the internal channel of the BTA tool even using low lubrication pressure. On the other hand, long chips will be more 
Table 8. Comparison between geometrical chip width ( $w$ from Eq. (1)), as a reference value, and chip width calculated over all cutting speeds, over all feed rates for each insert and as trace of chips flow on rake face of inserts.

\begin{tabular}{lccc}
\hline & $\begin{array}{c}\text { Central } \\
\text { Insert }\end{array}$ & $\begin{array}{c}\text { Intermediate } \\
\text { Insert }\end{array}$ & $\begin{array}{c}\text { External } \\
\text { Insert }\end{array}$ \\
\hline$w($ Eq. $(3))[\mu \mathrm{m}]$ & 4173 & 2775 & 3269 \\
$\bar{w}$ (over all $\left.V_{\mathrm{c}}\right)[\mu \mathrm{m}]$ & 3806 & 2575 & 3477 \\
$\bar{w}$ (over all $f)[\mu \mathrm{m}]$ & 3822 & 2509 & 3549 \\
$\bar{w}$ (trace of chips on rake face) $[\mu \mathrm{m}]$ & 3968 & 2579 & 3646 \\
$\frac{\bar{w}-w}{w}$ (over all $\left.V_{\mathrm{c}}\right)[\%]$ & 8.8 & 7.2 & 6.4 \\
$\overline{\bar{w}-w}$ (over all $f$ ) $[\%]$ & 8.4 & 9.6 & 8.6 \\
$\frac{\bar{w}-w}{w}$ (trace of chips on rake face) $[\%]$ & 4.9 & 7.1 & 11.5 \\
\hline
\end{tabular}
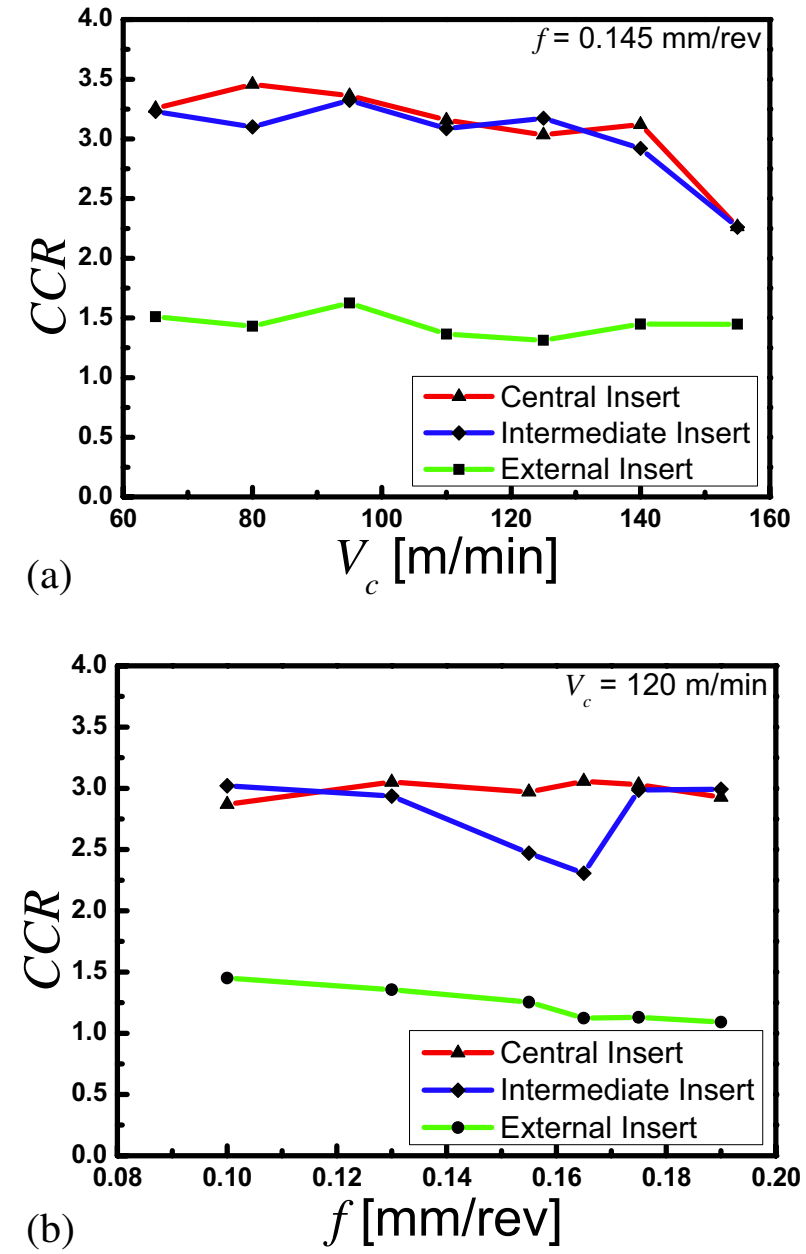

Fig. 12. Chip compression ratio as function of (a) cutting speed and (b) feed rate.

difficult to evacuate and present a risk of chips blockage in the BTA tool channel. A high lubrication pressure is then necessary, which also presents a risk for operators. The chips size is defined mainly by the width and length of chips. The chips width, as shown in Section 5.3.1, is quasi-independent of cutting conditions and it is related to the BTA tool geometry (position and inclination of inserts). On the other hand, the chips length, as shown in Figure 13, depends clearly on the cutting speed and feed rate. From Figure 13, the cutting speed has a little influence, compared to the feed rate, on the chips length.
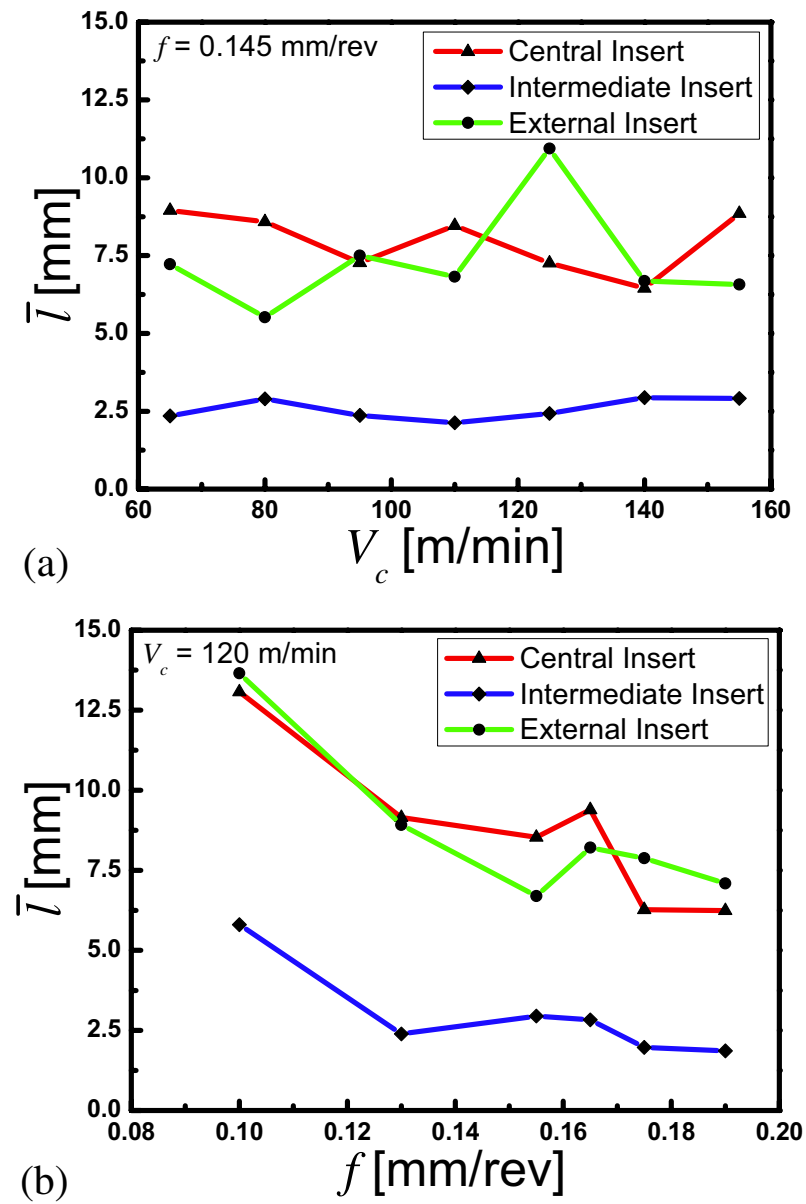

Fig. 13. Influence of (a) cutting speed and (b) feed rate on the chips length.

Indeed, increasing the feed rate, in the browsed range, decreases drastically the length of generated chips by all inserts. Noting that, central and external inserts generate longer chips, having the same order of length, but with more curvature for chips generated by the central insert (spiral shape).

Since the chips length is related to the fragmentation process of chips under specified cutting conditions, the proposed chip fragmentation parameter $(C F R)$ (see Sect. 4.3), as the ratio between the average chip length $(\bar{l})$ and the undeformed chip thickness $\left(t_{1}\right)$, is then evaluated, as reported in Figure 14. This quantifies the chip 

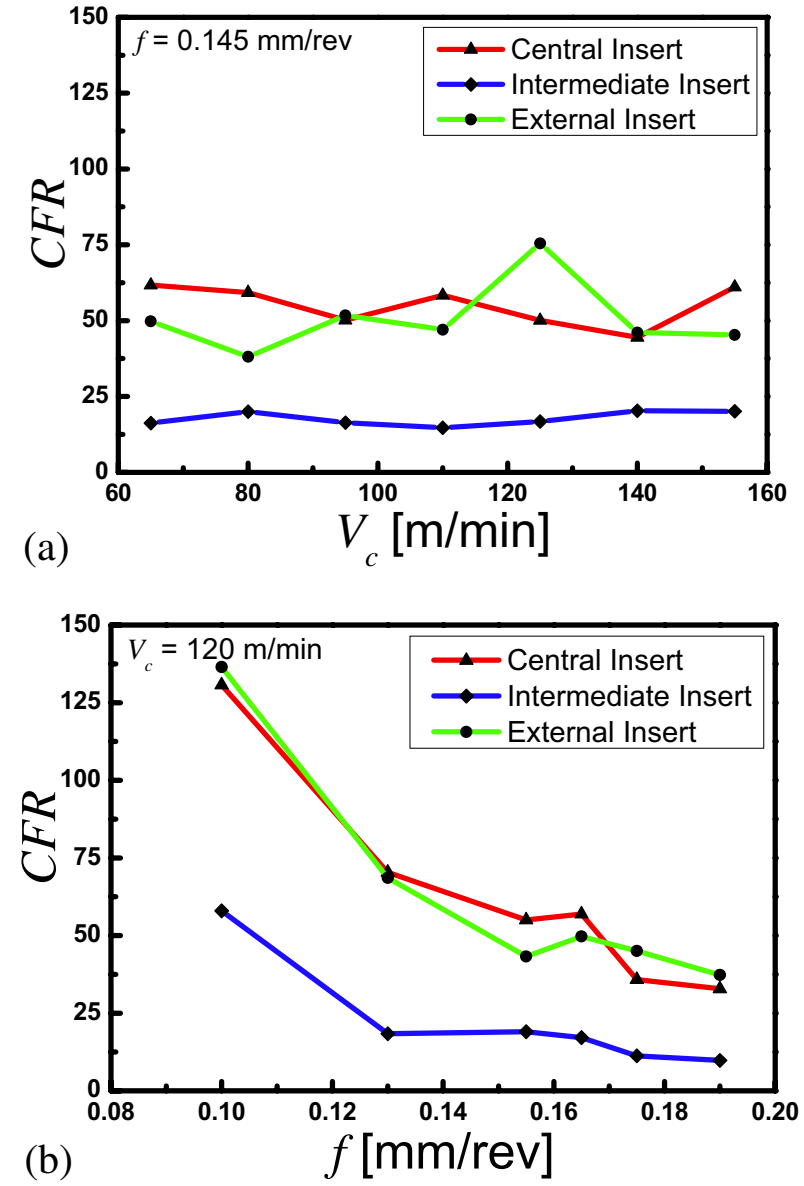

Fig. 14. Influence of (a) cutting speed and (b) feed rate on the chips fragmentation.

fragmentation phenomenon. It is shown that the $C F R$ as function of the cutting speed follows a similar evolution of the chips length (see Fig. 13a). By cons, the $C F R$ as function of the feed rate decreases for all chips generated by BTA drilling tool inserts. Clearly, the chip fragmentation phenomenon is more affected by the feed rate than by the cutting speed. This corroborates ascertainment of the tool manufacturer [47], which suggests that shorter chips are obtained by increasing the feed rate.

\subsection{Discussion about optimal cutting conditions for BTA deep hole drilling}

Criteria for choosing optimal cutting conditions in some drilling processes are given by Barlier [54]. In the present study, for a given workmaterial (18MND5) and BTA drilling tool, optimal cutting conditions can be defined by the analysis of the evolution of proposed chip morphology parameters with respect to cutting speed and feed rate variation. Identified pertinent parameters to choose optimal cutting conditions are the $C F R$, giving an indication about the chips size, and the $C C R$, giving an indication of the amount of plastic strain in generated chips. To improve the chips evacuation, varying the cutting speed is less pertinent, but increasing the feed rate reduces drastically the chips size and facilitates their evacuation accordingly, even using a low lubrication pressure. However limitation of the cutting speed, which allows reducing the amount of plastic strain in chips, or the feed rate, which allow reducing the chips size, is necessary. Indeed, excessive cutting speed or feed rate has a negative effect on the tool life. Increasing the feed rate will increase the flank wear, particularly for the central insert which penetrates first in the workmaterial. This is also the case for conventional drilling processes, where feed rate should be limited to avoid negative effective clearance angle (angle between the flank face and the newly machined surface), which highly increases the flank wear. While increasing excessively the cutting speed drastically increases the crater wear at rake faces of inserts. Determination of an optimal range of cutting conditions for BTA deep hole drilling should consider all these aspects for a given tool/workmaterial couple.

\section{Conclusions}

The BTA deep hole drilling process, when machining the 18MND5 steel, has been analysed based on the characterisation of chips generated by the three inserts of the cutting tool. A quantitative analysis, using adequate parameters, has been proposed. Hereafter some concluding remarks about obtained results:

(1) Macroscopic observations of generated chips did not allow highlighting the impact of cutting conditions on the cutting process, since chips, as function of cutting speed or feed rate, are difficult to distinguish at this scale. Hence a quantitative analysis based on geometrical characteristics of chips, using adequate parameters (chip width, chip length, chip compression ratio and chip fragmentation ratio), is shown more pertinent.

(2) It is shown that the influence of the cutting speed and feed rate on the chips width is very negligible and the last one can be approximated geometrically. This concludes that the chip formation occurs under quasi plane strain condition (no lateral strain, i.e. along cutting edges, that may change the chips width).

(3) The evaluation of the chip compression ratio has shown that increasing the cutting speed the $C C R$ of chips generated by the central and intermediate inserts decreases. For chips generated by the external insert the $C C R$ remains quasi constant. While increasing the feed rate the $C C R$ fluctuates around a fixed value for each set of chips generated by inserts.

(4) The chip fragmentation ratio has been introduced as a new parameter to quantify the chip fragmentation phenomenon. It has been shown that the chip fragmentation is highly influenced by the feed rate and quasi-independent of the cutting speed for the considered tool/workmaterial couple. Increasing the feed rate decreases the chip length (promote the chip fragmentation), which facilitates the chips evacuation. 
However the feed rate should not be increased excessively, since in such case it generates more solicitation of the BTA drilling tool, which leads to an excessive flank wear and in extreme case the locking of the BTA drilling head in the hole.

The usefulness of proposed parameters to analyse quantitatively and qualitatively the impact of cutting conditions on the cutting process is clearly highlighted. The proposed methodology can be applied for instance for conventional drilling process or some other cutting processes.

Acknowledgements. The authors wish to acknowledge the direction of AREVA Company for their acceptance and contribution to perform experimental tests in their manufacture site of Chalon sur Saône (France).

\section{References}

[1] R. Richardson, R. Bhatti, A review of research into the role of guide pads in BTA deep-hole machining, J. Mater. Process. Technol. 110 (2001) 61-69

[2] J. Jung, J. Ni, Prediction of coolant pressure and volume flow rate in the gundrilling process, J. Manuf. Sci. Eng. 125 (2003) 696-702

[3] J. Frazao, S. Chandrashekhar, M.O.M. Osman, T.S. Sankar, On the design and development of a new BTA Tool to increase productivity and workpiece accuracy in deep hole machining, Int. J. Adv. Manuf. Technol. 1 (1986) 3-23

[4] B.J. Griffiths, An investigation into the role of the burnishing pads in the deep hole drilling process, Ph.D. thesis of Brunel University (1982)

[5] B.J. Griffiths, Deep hole drilling and boring, The production Engineer (1975) 98-105

[6] K. Sakuma, K. Taguchi, A. Katsuki, H. Takeyama, Self guiding action of deep hole drilling tools, CIRP Annals Manuf. Technol. 30 (1981) 311-315

[7] K. Sakuma, K. Taguchi, A. Katsuki, Study on deep-holedrilling with solid-boring tool - the burnishing action of guide pads and their influence on hole accuracies, Bull. Japan Soc. Mech. Eng. 23 (1980) 1921-1928

[8] K. Sakuma, K. Taguchi, S. Kinjo, Study on deep hole drilling with solid boring tools - the effect of tool material on the cutting performance, Bull. Japan Soc. Mech. Eng. 21 (1978) 532-542

[9] M.C. Shaw, C.J. Oxford, On the drilling of metals II The torque and thrust in drilling, Trans. ASME 79 (1957) $139-148$

[10] W. Theis, O. Webber, C. Weihs, Statistics, dynamics and quality - Improving BTA-deep-hole drilling", Technical Report 6/2004 of the SFB 475, University of Dortmund (2004)

[11] M. Al-Ata, M.T. Hayajneh, An investigation of bell mouthing in precision hole machining with self-piloting tools, Int. J. Adv. Manuf. Technol. 43 (2009) 22-32

[12] K. Weinert, T. Bruchhaus, Tribological investigations into the operational behavior of self-piloting drilling tools, Wear 225-229 (1999) 925-935
[13] C.S. Deng, J.H. Chin, Roundness errors in BTA drilling and a model of waviness and lobing caused by resonant forced vibrations of its long drill shaft, J. Manuf. Sci. Eng. 126 (2004) 524-534

[14] C.S. Deng, J.C. Huang, J.H. Chin, Effects of support misalignments in deep-hole drill shafts on hole straightness, Int. J. Mach. Tools Manuf. 41 (2001) 1165-1188

[15] A. Al-Hamdan, Effect of misalignment on the cutting force signature in drilling, J. Mater. Process. Technol. 124 (2002) 83-91

[16] C.S. Deng, J.H. Chin, Hole roundness in deep-hole drilling as analysed by Taguchi methods, Int. J. Adv. Manuf. Technol. 25 (2005) 420-426

[17] N. Guibert, H. Paris, J. Rech, A numerical simulator to predict the dynamical behavior of the self-vibratory drilling head, Int. J. Mach. Tools Manuf. 48 (2008) $644-655$

[18] K. Weinert, O. Webber, C. Peters, On the influence of drilling depth dependent modal damping on chatter vibration in BTA deep hole drilling, CIRP Ann. - Manuf. Technol. 54 (2005) 363-366

[19] K. Weinert, O. Webber, M. Hüsken, J. Mehnen, W. Theis, Analysis and prediction of dynamic disturbances of the BTA deep hole drilling process, Proceedings of the Third CIRP International Seminar on Intelligent Comput. Manuf. Eng. (2002) 297-302

[20] K. Weinert, O. Webber, M. Hüsken, J. Mehnen, Statistics and time series analyses of BTA deep hole drilling, International Conference on Non-linear Dynamics in Mechanical Processing, 2001

[21] A. Messaoud, C. Weihs, Monitoring a deep hole drilling process by nonlinear time series modeling, J. Sound Vib. 321 (2009) 620-630

[22] A. Messaoud, C. Weihs, F. Hering, Detection of chatter vibration in a drilling process using multivariate control charts, Comput. Stat. Data Anal. 52 (2008) 3208-3219

[23] D. Biermann, A. Sacharow, K. Wohlgemuth, Simulation of the BTA deep-hole drilling process, Prod. Eng. Res. Dev. 3 (2009) 339-346

[24] N. Raabe, O. Webber, W. Theis, Spiralling in BTA deephole drilling: models of varying frequencies, From Data and Information Analysis to Knowledge Engineering, Studies in Classification, Data Analysis, and Knowledge Organization (2006) 510-517

[25] V.P. Astakhov, M.O.M. Osman, An analytical evaluation of the cutting forces in self piloting drilling using the model of shear zone with parallel boundaries. Part 1: Theory, International J. Machine Tools Manuf. 36 (1996) $1187-1200$

[26] V.P. Astakhov, M.O.M. Osman, An analytical evaluation of the cutting forces in self piloting drilling using the model of shear zone with parallel boundaries. Part 2: Application, Int. J. Machine Tools Manuf. 36 (1996) $1335-1345$

[27] F. Kea, J. Nib, D.A. Stephenson, Chip thickening in deephole drilling, Int. J. Machine Tools Manuf. 46 (2005) $1500-1507$

[28] F. Kea, J. Nib, D.A. Stephenson, Continuous chip formation in drilling, Int. J. Machine Tools Manuf. 45 (2005) $1652-1658$

[29] C.H. Gao, K. Cheng, D. Kirkwood, The investigation on the machining process of BTA deep hole drilling, J. Mater. Process. Technol. 107 (2000) 222-227 
[30] J. Thil, C. Barlier, B. Haddag, Introduction au forage profond : Technologies et étude du procédé, Magazine Equip'Prod 36 (2012)

[31] R. Komanduri, R.H. Brown, On the mechanics of chip segmentation in machining, J. Eng. Industry 103 (1981) $33-51$

[32] J. Barry, G. Byrne, D. Lennon, Observations on chip formation and acoustic emission in machining Ti-6Al-4V Alloy, Int. J. Mach. Tools Manuf. 41 (2001) 1055-1070

[33] J.D. Puerta Velásquez, B. Bolle, P. Chevrier, G. Geandier, A. Tidu, Metallurgical study on chips obtained by high speed machining of a Ti-6 wt. $\% \mathrm{Al}-4$ wt. $\% \mathrm{~V}$ alloy, Mater. Sci. Eng. A 452-453 (2007) 469-474

[34] Y. Wang, B. Li, G.Tu, The study on the chip formation and wear behavior for drilling forged steel S48CS1V with TiAlN-coated gun drill, Int. J. Refract. Metals Hard Mater. 30 (2012) 200-207

[35] S. Atlati, B. Haddag, M. Nouari, M. Zenasni, Analysis of a new Segmentation Intensity Ratio "SIR" to characterize the chip segmentation process in machining ductile metals, Int. J. Mach. Tools Manuf. 51 (2011) 687-700

[36] S. Kouadri, K. Necib, S. Atlati, B. Haddag, M. Nouari, Quantification of the chip segmentation in metal machining: Application to machining the aeronautical aluminium alloy AA2024-T351 with cemented carbide tools WC-Co. Int. J. Mach. Tools Manuf. 64 (2013) 102-113

[37] M. Cotterell, G. Byrne, Characterisation of chip formation during orthogonal cutting of titanium alloy TI-6Al4V, CIRP J. Manuf. Sci. Technol. 1 (2008) 81-85

[38] M.A. Davies, T.J. Burns, C.J. Evans, On the dynamics of chip formation in machining hard metals, Ann. ClRP 46 (1997) 25-30

[39] M.A. Davies, Y. Chou, C.J. Evans, On chip morphology, tool wear and cutting mechanics in finish hard turning, Ann. ClRP 45 (1996) 77-82

[40] L. Zhanqiang, S. Guosheng, Characteristics of chip evolution with elevating cutting speed from low to very high, Int. J. Mach. Tools Manuf. 54-55 (2012) 82-85

[41] S. Sun, M. Brandt, M.S. Dargusch, Characteristics of cutting forces and chip formation in machining of titanium alloys, Int. J. Mach. Tools Manuf. 49 (2009) 561-568
[42] A. Akhavan Farid, S. Sharif, M.H. Idris, Chip morphology study in high speed drilling of Al-Si alloy, Int. J. Adv. Manuf. Technol. 57 (2011) 555-564

[43] J. Barry, G. Byrne, The mechanisms of chip formation in machining hardened steels, J. Manuf. Sci. Eng. 124 (2002) 528-535

[44] A.E. Bayoumi, J.Q. Xie, Some metallurgical aspects of chip formation in cutting Ti-6 wt\%Al-4 wt\% V alloy, Mater. Sci. Eng. A 190 (1995) 173-180

[45] M.C. Shaw, A. Vyas, The mechanism of chip formation with hard turning steel, CIRP Ann. Manuf. Technol. 47 (1998) $77-82$

[46] V.P. Astakhov, S. Shvets, The assessment of plastic deformation in metal cutting, J. Materials Process. Technol. 146 (2004) 193-202

[47] SANDVIK Coromant, Deep hole drilling, Product catalogue and application guide (2003)

[48] S.R. Bordet, B. Tanguy, J. Besson, S. Bugat, D. Moinereau, A. Pineau, Cleavage fracture of RPV steel following warm pre-stressing: micromechanical analysis and interpretation through a new model, Fatigue Fract. Engng. Mater. Struct. 29 (2006) 799-816

[49] M. Hajjaj, Propagation dynamique et arrêt de fissure de clivage dans un acier bainitique, Ph.D. thesis of Ecole Centrale Paris 2006

[50] M. Hajjaj, C. Berdin, P. Bompard, S. Bugat, Analyses of cleavage crack arrest experiments: influence of specimen vibration, Eng. Fracture Mech. 75 (2008) 1156-1170

[51] B. Vereecke, Une analyse probabiliste du comportement d'une famille d'aciers pour cuve de REP en cas d'accident grave, Ph.D. thesis of Paris VI University, 2004

[52] V. Le Corre, Etude de la compétition déchirure ductile/rupture fragile : application a la tenue mecanique des tubes en acier C-Mn et de leurs joints soudes, Ph.D. thesis of Ecole Centrale Lille, 2006

[53] E. Merchant, Basic mechanics of the metal cutting process, J. App. Mech., Trans. ASME 66 (1944) A-168

[54] C. Barlier, Usinage des matériaux métalliques, Memotech Plus, Industrialisation \& Mécanique, Editions Casteilla, ISBN: 978-2-7135-2703-6 2010, ISSN: 0986-4024 